\title{
A PROVÍNCIA PEGMATÍTICA ORIENTAL DO BRASIL À LUZ DOS CONHECIMENTOS ATUAIS
}

\author{
JOSÉ M. CORREIA NEVES*, ANTONIO C. PEDROSA SOARES* \\ e VITÓRIA RÉGIA P.R.O. MARCIANO*
}

\begin{abstract}
This paper deals with the present knowledge level about pegmatites from the huge brazilian eastern pegmatitic province. Attention was given to: systematic and metamorphic control of pegmatites; metallogenetic age and geological setting of the province; structure of the rocks governing the morphology of pegmatites; primary mineralogy and geochemistry; and the genetic links between granites and pegmatites. This was dared even having in mind the actual size of the province and the scarcity of reliable evidences at the present time. The pegmatites throughout the Araçuaí district seem to have evolved from biotitic granites and forceful injected their host metamorphic rocks. However not all seem to point to the same crustal depths of emplacement and crystallization. So while the Itinga pegmatites, carrying petalite and spodumen + quartz or spodumen only, were emplaced in andalusite and cordierite schists of intermediate depths, the Coronel Murta ones, lacking in petalite, are found in kyanite schists from deeper crustal levels. The genetic links among at least some granites and pegmatites, in the Galiléia region, seem to be like those of Coronel Murta. The same can not be said about the pegmatites from Marilac where up to the present time no one of the genetic links with granites, not even in the field, could be traced. In the last two areas, at least in the Marilac one, the metamorphism graded up to the anatetic field. The metallogenetic potential for $\mathrm{Li}, \mathrm{Rb}, \mathrm{Cs}$ and $\mathrm{Ta}$ can be increasingly arranged as follows: Marilac, Galiléia, Coronel Murta, and Itinga the last one being the best know and promising spot.
\end{abstract}

INTRODUÇÃo Desde os anos 40 esta província se encontra delimitada (Paiva 1946). Ocupa uma faixa enorme, com cerca de $800 \mathrm{~km}$.de extensão por 100 a $150 \mathrm{~km}$ de largura, estendendo-se, de NNE para SSW, ao longo da parte oriental do Estado de Minas (Fig. 1). Em sua extremidade NE, já no Estado da Bahia, situa-se a chamada Província Pegmatítica de Itambé (Misi \& Azevedo 1971, 1975), ao passo que seu extremo sul foi denominado Província Pegmatítica da Zona da Mata (Barbosa \& Grossi Sad 1983). Os limites da Província, particularmente os oriental e meridional, indicados por Putzer (1976), têm de ser revistos, pois não englobam pegmatitos do Espírito Santo (Orcioli et al. 1978) e da Serra dos Órgãos, no Estado do Rio de Janeiro (Siga Jr. et al. 1982).

Raramente tem havido, nos estudos desta província, uma clara intenção que procure estabelecer as ligações entre as morfologia, mineralogia e geoquímica dos corpos pegmatíticos e seu enquadramento geológico, por isso estamos ainda muito longe de sua correta caracterização (Correia Neves 1981).

SISTEMÁTICA DAS FORMAÇÕES PEGMATITICAS No sentido de obter parâmetros que permitam visualizar de um ponto de vista científico os milhares de pegmatitos ocorrendo nesta província tomar-se-à como referência para reflexão a sistemática das formações pegmatíticas elaboradas por Rudenko et al. (1975) e Ginsburg et al. (1979), e divulgada no mundo ocidental por Černý (1982a) e Černý \& Burt (1984). Esta sistemática é, em resumo, a seguinte:

1. Pegmatitos abissais - Estão encaixados em formações metamórficas de fácies anfibolito alto a granulítica. São quase autóctones e originados por fusão parcial dos metamorfitos de alto grau, que os encaixam, sob pressões de 5 a $8 \mathrm{kbar}$ (cerca de 17 a $27 \mathrm{~km}$ de profundidade). Localmente, estão enriquecidos em $\mathrm{U}, \mathrm{Th}, \mathrm{TR}$ (terras raras), $\mathrm{Nb}, \mathrm{Ti}$ e $\mathrm{Zr}$.

2. Pegmatitos moscovíticos - São característicos das formações com metamorfismo barrowiano de alta pressão e encaixados em micaxistos de fácies almandina-anfibolito, subfácies cianita + almandina, de Winkler (1967), essencialmente, fora da isógrada da estaurolita e abaixo da primeira isógrada da silimanita. Originam-se por anatexia ou fracionamento restrito de granitos primitivos mais ou menos autóctones, de 4 a $6 \mathrm{kbar}$ ( 13 a $20 \mathrm{~km}$ de profundidade) e consolidam-se próximo do foco da geração magmática. São depósitos de moscovita e feldspato potássico, e apresentam ocasionalmente conteúdos subordinados de Be, $\mathrm{Nb}, \mathrm{TR}, \mathrm{U}$ e Th.

3. Pegmatitos com elementos-raros - São característicos de formações com metamorfismo tipo Abukuma de baixa pressão, gerados por fracionamento de granitos alóctones diferenciados e consolidados entre 2 e $4 \mathrm{kbar}$ ( 7 a $13 \mathrm{~km}$ de profundidade), sobretudo em rochas de fácies anfibolito com cordierita, na subfácies andalusita + cordierita + moscovita, de Winkler (1967). Em sua maior parte ocorrem além das isógradas da cordierita e da estaurolita, e abaixo da primeira isógrada da silimanita. Um ou mais dos elementos $\mathrm{Li}, \mathrm{Rb}, \mathrm{Cs}, \mathrm{Be}, \mathrm{Sn}, \mathrm{Nb}, \mathrm{Ta}, \mathrm{Zr}, \mathrm{Hf}, \mathrm{Ga}, \mathrm{Bi}$ e Mo, com ou sem quantidades significativas de $\mathrm{B}, \mathrm{Pe} / \mathrm{ou} \mathrm{F}$, estão enriquecidos nesta classe que pode ser subdividida em:

- Tipo rico em gadolinita (Be, Y, TR, $\mathrm{Nb} \gtrless \mathrm{Ta}, \mathrm{Ti}$, U, Th).

- Tipo rico em berilo-columbita (Be, $\mathrm{Nb} \gtrless \mathrm{Ta} ; \pm \mathrm{Sn}, \mathrm{TR}$, P, B).

- Tipo de pegmatitos complexos zonados ou bandados $(\mathrm{Li}$, $\mathrm{Rb}, \mathrm{Cs}, \mathrm{Be}, \mathrm{Ta}>\mathrm{Nb}, \mathrm{Sn} ; \pm \mathrm{B})$.

- Tipo quase-homogêneo com espodumênio $(\mathrm{Li}, \mathrm{Be}, \mathrm{Nb} \geqslant$ $\mathrm{Ta} ; \pm \mathrm{Sn})$.

- Tipo rico em lepidolita $(\mathrm{F}, \mathrm{Li}, \mathrm{Rb}, \mathrm{Be}, \mathrm{Ta}>\mathrm{Nb}$; $\pm \mathrm{Cs}$, $\mathrm{Sn})$. 


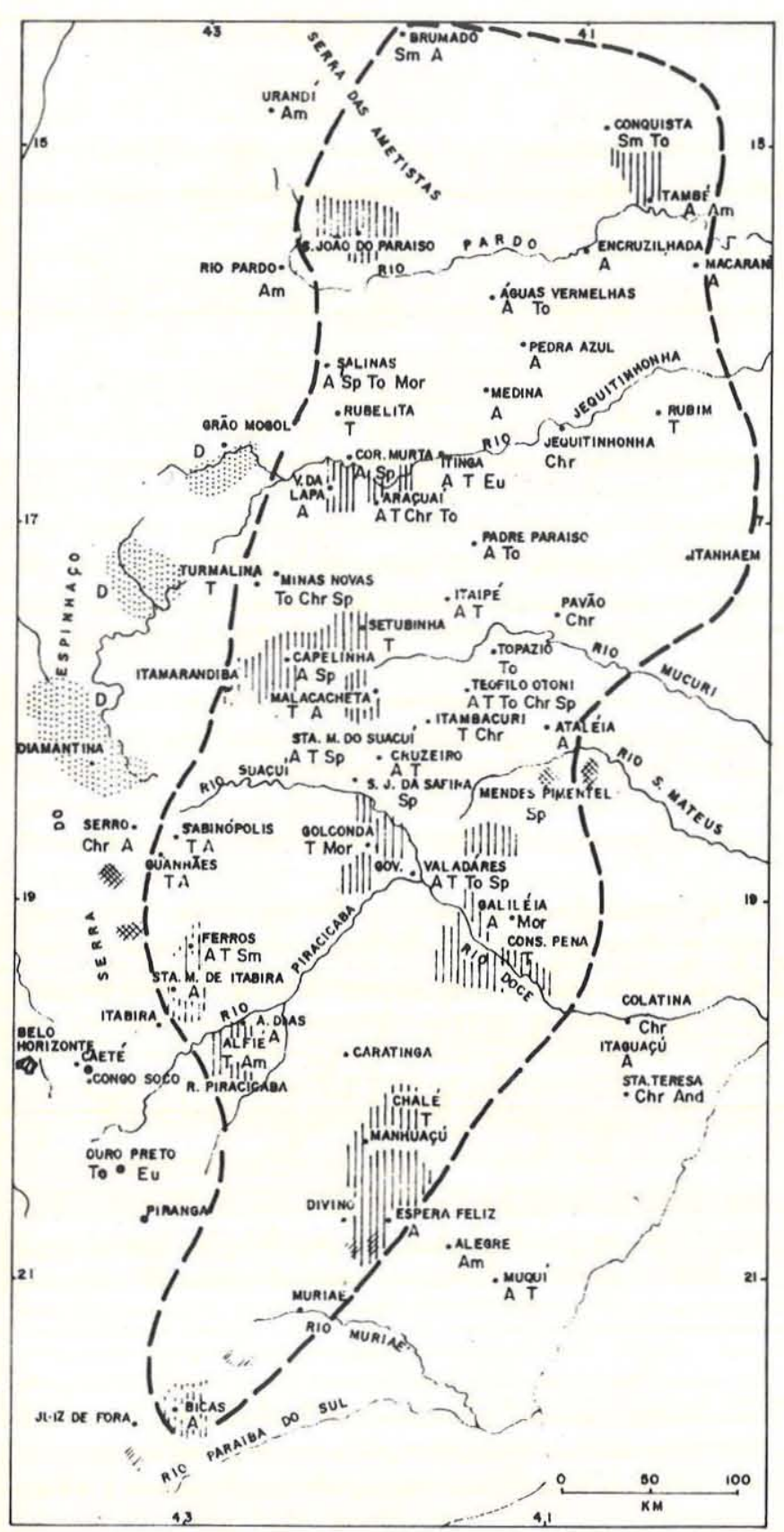

Figura 1 - Provincia Pegmatitica Oriental (traços verticais, pegmatitos ricos em micas; traços inclinados, aluviões $\mathrm{Au}$; ponteado, diamante; linhas cruzadas, aluviões $\mathrm{Pt}$; $A$, berilo; $S m$, esmeralda; Mor, morganita; $T$, turmalina; To, topázio; $\mathrm{Sp}$, espodumênio; $\mathrm{Chr}$, crisoberilo; And andalusita, $\mathrm{Am}$, ametista; Eu, euclásio), segundo Putzer 1976

4. Pegmatitos miarolíticos - Estes estão confinados às cúpulas de granitos alóctones, epizonais a subvulcânicos, ocasionalmente de tipo hipersolvus, ou então nas vizinhanças imediatas desses granitos. Consolidaram-se a uma profundidade entre cerca de 3 a $6 \mathrm{~km}$ ( 1 a 2 kbar). Aparecem em veios preenchendo fraturas ou em bolsões com o mesmo modelo de enriquecimento em elementos-traços que o dos pegmatitos com elementos raros. Podem conter quartzo piezoelétrico e fluorita óptica.
Informações mais detalhadas sobre esta sistemática podem ser obtidas em Černý (1982a e b, 1984) e Černý \& Burt (1984).

\section{IDADE DA PROVINCIA PEGMATIITICA ORIENTAL DO}

BRASIL A idade das informações pegmatíticas da Província Oriental parece ligar-se à das manifestações pós-tectônicas tardias da Orogenia Brasiliana. Localmente, isto já foi seguramente demonstrado.

Dirac \& Ebert (1967) dataram, pelo método K-Ar, moscovitas de um pegmatito de Manhuaçu e obtiveram valores de $556 \pm 16$ e $505 \pm 10 \mathrm{Ma}$. Esses autores apresentaram ainda dados obtidos também pelo método $\mathrm{K}-\mathrm{Ar}$ em duas moscovitas de um pegmatito de Bicas, no' extremo sul da Província Pegmatítica Oriental, que correspondem a $511 \pm$ 14 e $483 \pm 12 \mathrm{Ma}$, respectivamente.

Amostras de mica e feldspato provenientes da região de Eugenópolis-Caparaó (Cordani et al. 1973, Cordani \& Teixeira 1979) deram idades $\mathrm{Rb}-\mathrm{Sr}^{*}$ de $452 \pm 15 \mathrm{Ma}$ (moscovita) e $492 \pm 15 \mathrm{Ma}$ (feldspato) e de 469 Ma (moscovita, $\mathrm{K}-\mathrm{Ar}$ ).

Uma moscovita de um pegmatito ao norte de Galiléia (Governador Valadares-MG) deu uma idade K-Ar de $408 \pm$ $8 \mathrm{Ma}$ (Cordani 1973).

Na região de Araçuaí, Sá (1977) encontrou, pelo método $\mathrm{Rb}$-Sr, idades de $673 \mathrm{Ma}$ para o metamorfismo regional dos xistos e de $538 \mathrm{Ma}$ para os granitóides neles intrusivos. As relações ${ }^{87} \mathrm{Sr} /{ }^{86} \mathrm{Sr}$ dessas rochas graníticas são altas e permitem pensar que, na região de Araçuaí, tenham origem anatética. Moscovitas de dois pegmatitos, datadas pelo método K-Ar, dão idades em torno de $480 \mathrm{Ma}$

A mesma idade é admitida para os pegmatitos do sul da Bahia (Andrade et al. 1977, Pedreira et al. 1978), para os da região de Galiléia (Moura et al. 1978a) e mesmo nos do extremo sul, encaixados em formações do Grupo Paraíba, que sobreu reativação no decurso do Ciclo Brasiliano (Hasui et al. 1978).

Siga Jr. et al. (1982) apresentam uma revisão dos dados geocronológicos da parte setentrional da Faixa Ribeira. Nesse trabalho, de amostras coletadas em pegmatitos da Serra dos Órgãos (RJ), são referidas três datações K-Ar em micas $(471 \pm 14,464 \pm 25$ e $408 \pm 11 \mathrm{Ma})$ e uma $\mathrm{Rb}-\mathrm{Sr}$ em feldspato (512 $\pm 19 \mathrm{Ma})$. Estes resultados permitem estender, englobando a Serra dos Órgãos, o limite meridional da Província Oriental.

Determinação de idade $\mathrm{Rb}$-Sr em feldspato potássico de um pegmatito aflorando na estrada de ferro, cerca de $5 \mathrm{~km}$ a sul de João Montevade, forneceu o valor de $545 \mathrm{Ma}$ (Teixeira 1982).

Em pegmatitos aflorando poucos quilômetros a oeste de Governador Valadares, foram obtidas idades $\mathrm{Rb}-\mathrm{Sr}$, em moscovita e microclina, de $497 \pm 13$ e $501 \pm 14$ Ma, respectivamente (Marciano 1985)

Pode-se, pois, concluir, dos dados de geocronologia obtidos nas porções setentrional, centro-oriental, oriental e meridional da província que houve geração de grande quantidade de material pegmatítico no fim do Ciclo Brasiliano. Isso permite afirmar que um grande número dos pegmatitos aflorantes na Província Oriental pertence a uma época metalogenética (Stanton 1972) desta mesma idade. 
ENQUADRAMENTO GEOLÓGICO DOS PEgMATITOS DA PROVINCIA ORIENTAL Analisando a figura 1, com extensas manchas de pegmatitos ricos em mica, podemos suspeitar de que estes se originaram por anatexia ou por fracionamento restrito de granitos "autóctones" posicionados entre 13 e $20 \mathrm{~km}$ de profundidade no esquema de sistematização das formações pegmatíticas desenvolvido pelos geólogos russos (Černy \& Burt 1984).

No sentido de tentar definir melhor o enquadramento geológico dos pegmatitos da Província Oriental, projetamos seus limites no fundo geológico de Schobbenhaus et al. $(1981,1984)$, conforme se mostra na figura 2. Da análise da figura, dá-se conta de que os pegmatitos da Província Oriental se posicionaram em formações cujas idades vão do Arqueano ao, possiveimente, Proterozóico Superior. Uma grande concentração desses pegmatitos localiza-se, porém, em grande mancha do chamado Pré-Cambriano indiviso, constituída por granitóides homófanos ou orientados, metapelitos e metapsamitos. Os granitóides do Proterozóico Superior e/ou Eopaleozóico parecem estar relacionados com muitos dos pegmatitos que ocorrem nesta Província (Sá 1977, Sá \& Ellert 1981, Correia Neves 1980, 1981, Correia Neves et al. 1980a e 1980b, 1982a, 1982b, 1984, Pedrosa Soares 1984, Barbosa et al. 1964, 1966).

Como estas formações de idade arqueana ou proterozóica foram retrabalhadas pelo menos durante o Transamazônico e/ou Brasiliano, pode ter-se gerado a partir delas material quartzo-feldspático correspondente a pegmatitos durante quaisquer desses ciclos (Hasui et al. 1976, Cordani \& Teixeira 1979).

Pegmatitos transamazônicos, já fora da Província Oriental, foram identificadas em Cláudio, a sudoeste de Belo Ho. rizonte com idades de $2.078 \pm 78 \mathrm{Ma}$. (Teixera 1982), e pro. ximo de Sete Lagoas (Pinson et al 1967), estes com idades $\mathrm{Rb}$ - $\mathrm{Sr}$ mais novas que os $2.100 \mathrm{Ma}$. correspondentes à isócrona dos gnaisses e granitos seus encaixantes (Teixeira 1982).

Na Bahia, no Complexo Contendas-Mirante, são referidos também pegmatitos transamazônicos com idade $\mathrm{K}$ - $\mathrm{Ar}$ determinada em moscovita de $1.892 \pm 70 \mathrm{Ma}$. (Brito Neves et al. 1980).

Os pegmatitos, ticos em $\mathrm{Li}$, de Volta Grande, São João del Rei, deram idades de $990 \mathrm{Ma}$, pelo método $\alpha-\mathrm{Pb}$ (Costa 1978) e de $1.186 \pm 98$ a $1.105 \pm 39 \mathrm{Ma}$. em micas datadas pelos K-Ar (Dirac \& Ebert 1967). Isso os coloca fora da Província Metalogenética Oriental do Brasil.

Apesar de ter-se de levar em conta os fatos assinalados anteriormente, os dados geocronológicos atualmente disponíveis indicam que o Brasiliano foi particularmente eficiente na geração de material granítico e pegmatítico, talvez por ter envolvido anatexia de formações metassedimentares mais recentes que o Transamazônico.

A maior informação que existe refere-se às regiōes de Araçuaí (Vale do Jequitinhonha), Governador Valadares e Galié́ia. Esta informação, ainda que incompleta em muitos aspectos, será analisada e interpretada no sentido de se começar a definir, dentro da enorme Província Pegmatítica Oriental do Brasil, áreas com certa homogeneidade. Na definição destas usar-se-á os seguintes parâmetros: 1) mineralogia acessória; 2) enquadramento geológico; e 3) atribu. tos geoquímicos dos pegmatitos por se julgar possível, a tos geoquímicos dos pegmatitos por julgarmos possivel a partir deles, caracterizar o grau de evolução da fusão pegmatítica.

PEGMATITOS DAS PORÇÕES SETENTRIONAL E CEN. TRO-ORIENTAL DA PROVINCIA PEGMATITICA ORIENTAL Os pegmatitos mais bem conhecidos da província situam-se no médio Vale do Rio Jequitinhonha (Sá 1977, Sá \& Ellert 1981, Correia Neves et al. 1980a, 1982a, 1982b, Correia Neves 1980, 1981, 1984, Pedrosa Soares 1984); nas partes média e alta do Rio Doce; e ao norte de Governador Valadares, até São José da Safira (Pécora et al. 1950, Barbosa et al. 1964, 1966, Moura et al. 1978a, 1978b, Fanton et al. 1978, Issa Filho et al. 1980, Correia Neves et al. 1980b, Wegner 1983; Marciano 1985).

Esses pegmatitos serão a seguir analisados quanto à forma, ao tamanho, à mineralogia* e ao condicionamento estrutural; à geoquímica de seus berilós, feldspatos e micas; às relações entre granitos e pegmatitos; e ao tipo do metamorfismo de suas encaixantes.

Os pegmatitos do médio Vale do Rio Jequitinhonha são normalmente tabulares ou lenticulares, têm estrutura zona$\mathrm{da}$, exceto os muito pequenos, e estão encaixados quer em micaxistos e quartzitos, quer nos granitóides parentes. Quando intrudidos nos metapelitos, normalmente concordam com o acamamento e/ou xistosidade. Mas os pegmatitos encaixados em quartzitos, que formam o núlceo de antiformes, como acontece nos do Vieirão e FecharFecha (Barra do Salinas) e da Serra da Lagoa Nova (Coronel Murta), estão intrudidos segundo dois sistemas de diáclases verticais (em E--W e outro N-S) e não segundo o acamamento e/ou xistosidade (Correia Neves et al. 1982a, Pedrosa Soares 1984). Denunciando um posicionamento forçado, alguns desenvolvem nos xistos encaixantes uma foliação local e incorporam xenólitos destes.

Distrito Pegmatítico de Araçuaí (médio Vale do Jequitinhonha) Nesta região, os pegmatitos estão sendo estudados pelos autores desde 1976. No decurso desse trabalho foi-se tornando claro que no distrito pegmatítico de Araçuaí se poderiam individualizar dois campos distintos. Passar-se-á designar um por campo pegmatítico de Coronel Murta-Virgem da Lapa e outro por campo pegmatítico de Itinga. Este último corresponde essencialmente à área estudada por Sá (1977).

A visão integrada do distrito pegmatítico de Araçuaí pode ter-se da carta (Fig. 2) que condensa informaçōes geológicas disponíveis na área até o presente.

\section{CAMPO PEGMATITICO DE CORONEL MURTA-VIRGEM} $D A$ LAPA Nesta região, os pegmatitos se encaixam quer nos metamorfitos quer nos granitóides, e estão geneticamente associados a estes últimos.

Os granitóides, divididos em biotita-moscovita granitos $\left(\gamma_{\mathbf{B}}\right)$, moscovita-biotita granitos $\left(\gamma_{M}\right)$ e granitos pegmatóides, caem no domínio granito-granodiorito de Strečkeisen (1973), com tendência alcalina (Correia Neves et al. 1982b, Pedrosa Soares 1984).

Pegmatitos encaixados em metamorfitos e granitóides Os pegmatitos encaixados em metamorfitos do proterozóico indiviso (Fig. 2), na área de Coronel Murta, posicionaram-se nas unidades (Psq) e (Psx) (Pedrosa Soares

* A mineralogia supergênica, ainda que muito interessante, não será considerada, pois depende de processos superficiais de intemperismo físico-químico, sem ligação com a gênese e evolução primária dos pegmatitos. 


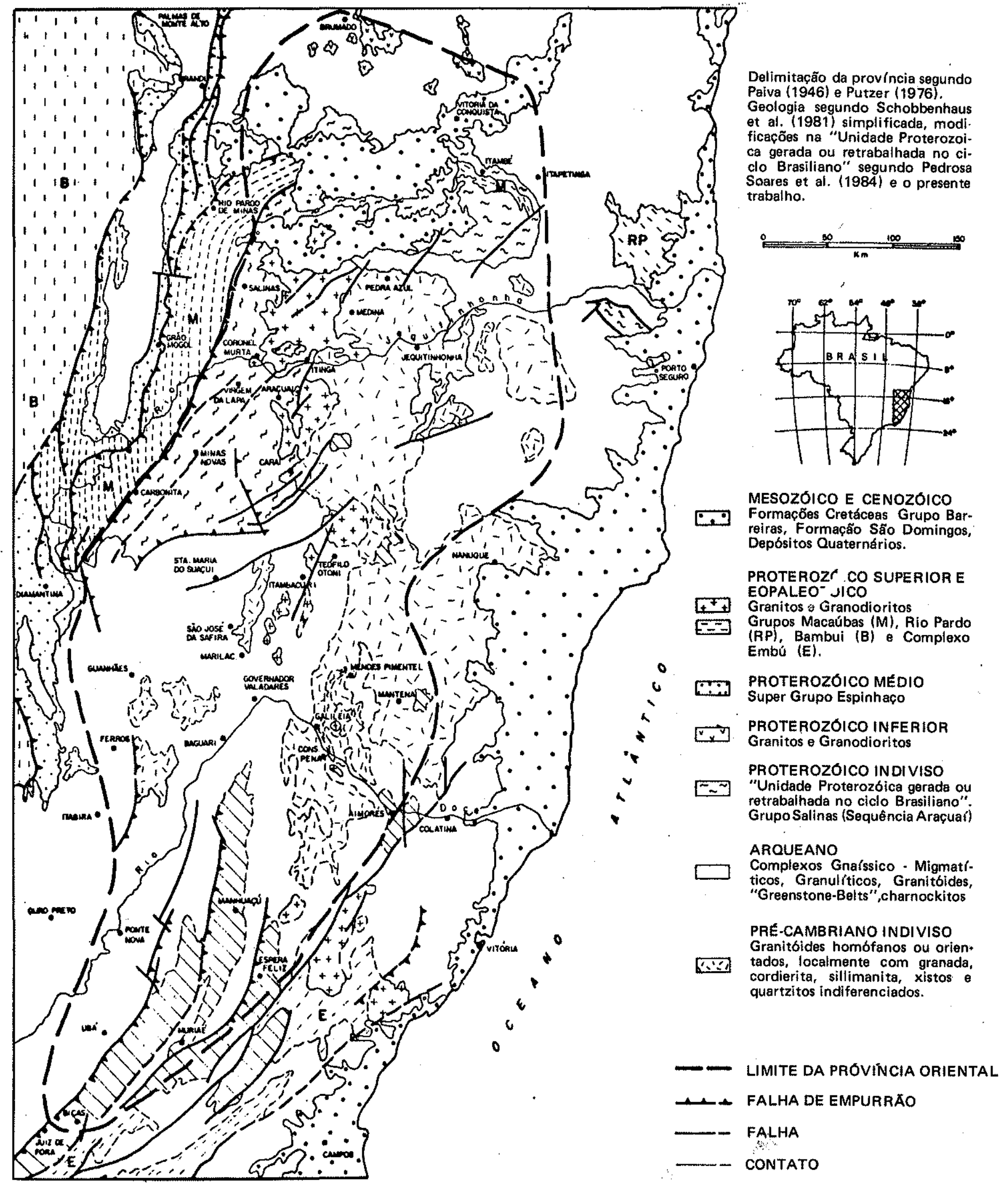

Figura 2 - A Provincia Pegmatitica Oriental em seu contexto geológico. Delimitação da provincia segundo Paiva (1946) $e$ Putzer (1976). Geologia segundo Schobbenhaus et al. (1981), simplificada, modificações na "unidade proterozóica gerada ou retrabalhada no ciclo brasiliano", segundo Pedrosa Soares et al. (1984) e o presente trabalho 
1984).

Os pegmatitos da unidade quartzítica (Psq) encaixam em sistemas de diáclases de alto mergulho com orientações E-W e N-S. Estes pegmatitos são pouco espessos (de 1 a $4 \mathrm{~m}$ ), estão fortemente intemperizados, têm estrutura zonada e apresentam corpos de substituição por vezes muito numerosos. Nesses pegmatitos, aos minerais essenciais das paragêneses primárias juntam-se, como acessórios: turmalinas (pretas e coradas); berilo prismático e tabular (raramente); ambligonita; cassiterita; e columbo-tantalita.

Os pegmatitos encaixados na unidade metapelítica (Psx) são divididos (Pedrosa Soares 1984) nos seguintes tipos:

I. Pegmatitos simples, homogêneos ou com zoneamento difuso.

II. Pegmatitos zonados simples, com mineralogia acessória pouco diversificada.

III. Pegmatitos complexos com volumosos corpos de substituição e diversificada mineralogia acessória.

Os pegmatitos simples (I) apresentam-se com maior abundância próximo dos contatos com os granitóides, alguns deles encaixam nas duas litologias, raramente têm mais de $1 \mathrm{~m}$ de espessura e por vezes discordam da xistosidade. Sua mineralogia acessória é constituída por moscovita, biotita e granada vermelha.

Os pegmatitos zonados simples (II) chegam a atingir espessuras superiores a $15 \mathrm{~m}$, encaixam concordando com a xistosidade e possuem pequenos e raros corpos de substituição. Sua mineralogia acessória é formada por schorlita, biotita, granada vermelha e berilo nas zonas primárias e por buchos de micas claras de granulação fina com, às vezes, cristais de turmalina corada.

Os pegmatitos complexos (III) encaixam segundo a xistosidade, contêm caracteristicamente minerais de $\mathrm{Li}$ e chegam a atingir espessuras superiores a $25 \mathrm{~m}$. Nestes corpos são evidentes as unidades tardias de substituição constituídas basicamente por cleavelandita e micas claras de granulação fina. Uma parte desses pegmatitos apresenta espodumênio. A mineralogia acessória, nas zonas primárias dos corpos, é formada por moscovita, schorlita, berilo prismático, biotita, almandina, columbita-tantalita e espodumênio, e a dos corpos tardios, dispersa na mineralogia básica, é constituída por cassiterita, ambligonita, morganita tabular, herderita, topázio, bismutinita, bismutita e diversos tipos de turmalinas coradas. Nos corpos de substituição desses pegmatitos ocorrem lepidolitas com teores em $\mathrm{Li}_{2} \mathrm{O}$ que variam entre $4,63 \%$ e $6,59 \%$ (Pedrosa Soares 1984). As micas tardias mostram acentuadas variações composicionais que se traduzem até mesmo por zoneamento observável em amostra de mão.

A ocorrência na lavra da Vereda, de crisoberilo pode significar assimilação pelo pegmatito de material metapelítico da encaixante (Heinrich \& Buchi 1969, Correia Neves 1984).

Além dos pegmatitos encaixados em metamorfitos, existem outros associados a granitos. Esses pegmatitos correspondem quer a bolsões de contatos difusos com os granitóides ricos em biotita, quer a corpos tabulares preenchendo fraturas dos mesmos granitóides.

Além da mineralogia básica, apresentam, normalmente como acessórios, schorlita, berilo prismático (muitas vezes na variedade água-marinha), biotita e granada vermelha. Os corpos tabulares subhorizontais, tais como a da lavra da Serra, apresentam assimetria de zoneamento com moscovita e schorlita situadas na capa, o que mostra uma diferenciação causada pelo campo gravitacional.

Quando esses pegmatitos estão encaixados nos moscovitas granitos, como resultado de um forte empobrecimento em $\mathrm{Fe}$, neles chegam a se encontrar turmalinas verdes, e algumas com qualidade gemológica.

CAMPO PEGMATITICO DE ITINGA Nesta região, os pegmatitos encaixam-se também nos metamorfitos e nos granitos dominantemente biotíticos. Ao lado destes ocorrem ainda granitos pegmatóides.

Os granitos, intrusivos nos xistos encaixantes, mostram xenólitos destes últimos com evidentes sinais de metassomatismo causado pelos granitos e que se traduz por um aumento considerável dos teores em Li, Be, Cs, Rb (Sá \& Ellert 1981) nos xenólitos. As mesmas relações geométricas foram mostradas por Costa et al. (1984).

Os pegmatitos da região foram classificados, em função das associações minerais, em simples e complexos. Em seus exocontatos notam-se auréolas enriquecidas em $\mathrm{Li}, \mathrm{Rb}, \mathrm{Zn}$, Cs e $\mathrm{Sn}$ relativamente ao teor médio destes elementos nos xistos. As que circundam os pegmatitos complexos apresentam teores mais altos nestes elementos e são muito mais largas do que as que envolvem os pegmatitos simples (Sá \& Ellert 1981).

Os pegmatitos simples formam corpos tabulares pouco espessos, com estrutura zonada, podendo atingir centenas de metros em afloramento. Ao lado dos feldspato e quartzo, que constituem mais de $90 \%$ do corpo, ocorrem ainda moscovita, schorlita e berilo. Esses pegmatitos são os mais abundantes na área e encaixam nos metamorfitos e, sobretudo, nas partes periféricas dos granitos. Neles não ocorrem minerais de Li. Neste tipo de pegmatitos e mesmo em veios de quartzo observa-se andaluzita, que deve corresponder à assimilação dos metapelitos encaixantes (Costa et al. 1984).

Os pegmatitos complexos são corpos de grandes dimensões com até dezenas de metros de largura e até $500 \mathrm{~m}$ de comprimento (lavra do Meio). São normalmente lenticulares. Apresentam estrutura zonada primária recortada por grandes volumes de substituição. Estão intrudidos exclusivamente nos xistos encaixantes dos granitos, orientados pela foliação dos xistos, ainda que, devido a seu grande volume e posicionamento forçado, apresentem sinais de discordância com as estruturas da encaixante. Dentro desses pegmatitos ocorrem xenólitos turmalinizados do xisto.

A mineralogia dos pegmatitos complexos é qualitativa e quantitativamente muito mais diferenciada que a dos pegmatitos simples. A mineralogia básica é formada, nas zonas primárias, por microclina, quartzo e moscovita, e nos corpos de substituição por cleavelandita e micas litiníferas (por vezes lepidolitas) de granulação fina. Em alguns pegmatitos, muito ricos em $\mathrm{Li}$, a petalita e/ou espodumênio cristalizam já durante o desenvolvimento das zonas primárias. Minerais exploráveis nesses pegmatitos, tais como ambligonita, turmalinas coradas, cassiterita, tantalita-columbita e polucita, são típicos dos corpos de substituição tardios. Acessórios da zona primária são turmalinas (preta, verde e azul-escuro), raramente, e berilo azulado prismático e tantalita-columbita. Acessórios dos corpos de substituição são, por vezes, litiofilita-trifilita, o mineral novo whiteita (Moore \& Ito 1978), morganita, cassiterita e tantalitas.

É de assinalar que, nestes pegmatitos complexos, a ocor- 
rência de lepidolita não coincide com o aparecimento de espodumênio. Nos pegmatitos, nos quais ocorre petalita, o espodumênio é subordinado e pseudomorfo depois da petalita ou não existe. Há pegmatitos com espodumênio e sem petalita (Sá 1977, Sá \& Ellert 1981).

Distrito Pegmatítico de Governador Valadares Os pegmatitos aflorando ao longo do Vale do Rio Doce e entre Governador Valadares e São José da Safira são predominan. temente tabulares, com razoável incidência dos lenticulares e pequena ocorrência de outras formas. Existem em muitos tamanhos, porém os mais bem mineralizados são os que têm espessura acima de $10 \mathrm{~m}$ e chegam a atingir possanças superiores a $50 \mathrm{~m}$. São corpos com zoneamento primário e unidades tardias no sentido de Cameron et al. (1949). Seu posicionamento nas rochas encaixantes está condicionado por estruturas desenvolvidas antes da geração do material pegmatítico. Cerca de $85 \%$ dos pegmatitos estudados por Issa Filho et al. (1980) são concordantes quer com a foliação das rochas xistosas, quer com sistemas de fraturas de granitóides, gnaisses e quartzitos.

Turmalinização e moscovitização são freqüentes nos exocontatos dos pegmatitos. Denunciando um posicionamento forçado do material dos pegmatitos, aparece, nos xistos encaixantes de pegmatitos de Galiléia, xistosidade secundária (Fanton et al. 1978).

Os trabalhos do pessoal de Metamig (Metais de Minas Gerais), particularmente o de Issa Filho et al. (1980), permitem caracterizar neste distrito os importantes campos pegmatíticos de 1) Galiléia-Conselheiro Pena a leste de Governador Valadares, que ocupa uma faixa NW-SE desde Aimorés até Mendes Pimentel e 2) Marilac a oeste de Governador Valadares, que ocupa uma faixa $\mathrm{N}-\mathrm{S}$ desde Baguari até São José da Safira. A visão integrada desses campos pode ter-se pela carta (Fig. 2) que condensa informaçōes geológicas disponíveis na área até o presente.

\section{CAMPO PEGMATITICO DE GALILEIA-CONSELHEIRO}

PENA Na área, os pegmatitos encaixam quer nos mican $\mathrm{x}$ istos (peBCmx) colocados por Schobbenhaus et al. (1978a) no topo do proterozóico inferior, que nos granitóides $\left(\mathrm{p} \epsilon \mathrm{A} \gamma_{2}\right)$ do proterozóico superior (Schobbenhaus et al. (1978a). Estes últimos pegmatitos estão geneticamente associados aos granitóides.

Pegmatitos encaixados nos metamorfitos e nos granitos Neste campo pegmatítico, cerca de $88 \%$ dos pegmatitos com interesse econômico encaixam no micaxisto São Tomé (Barbosa et al. 1964, 1966, Fanton et al. 1978). São comuns xenólitos deste dentro dos pegmatitos.

Em sua maioria, os pegmatitos estão encaixados seguin. do a xistosidade, predominantemente orientada $\mathrm{N}-\mathrm{S}$, embora varie entre $\mathrm{N} 20 \mathrm{O}_{\mathrm{E}}$ e N20OW (Moura et al. 1978a). São corpos com estrutura zonada. Sua mineralogia básica é formada por quartzo e feldspato pertítico, nas unidades de cristalização primária, e cleavelandita e mica clara de granulação fina, nạs unidades metassomáticas tardias. A mineralogia acessória é constituída por 1) biotita, moscovita, afrisita, berilo prismático, columbita-tantalita, espodumênio e granada, nas unidades de cristalização primária e 2) trifilita, brazilianita, ambligonita e outros fosfatos primários, turmalinas coradas, morganita tabular, topázio, sulfetos, Nb-tantalitas, fosfatos produtos da atividade hidrotermal (Correia Neves et al. 1980b, Lindberg 1958), cassiterita, stokesita e outros, nas unidades metassomáticas tardias.

Um número relativamente pequeno de pegmatitos (cerca de $12 \%$ ), dos que têm interesse econômico, associa-se diretamente aos granitos, onde preenchem fraturas e formam bolsões, estes de contatos difusos com o granito. São normalmente pegmatitos simples, com mineralogia acessória muito pouco diversificada (Fanton et al. 1978).

CAMPO PEGMATITTICO DE MARILAC Nesta região, os pegmatitos estão encaixados num complexo gnáissico. migmatítico (peCD) (Schobbenhaus et al. 1978b) considerado do proterozóico inferior e não apresentam granitóides isotrópicos em sua vizinhança imediata (Marciano 1985).

Dos muitos pegmatitos deste campo, só dois deles (Ferreirinha e Olho de Gato) foram estudados em pormenor (Marciano 1985). Raramente se encontram minerais de $\mathrm{Li}$, ainda que o espodumênio, micas litiniferas e turmalinas elbaíticas sejam assinaladas (Putzer 1976).

Nestes pegmatitos, os minerais acessórios das unidades de cristalização primária são: berilo prismático (às vezes água-marinha), almandina, biotita e columbo-tantalitas muito pobres em $\mathrm{Ta}_{2} \mathrm{O}_{5}$ (Marciano 1985). Em muitos corpos, as unidades metassomáticas, constituídas por cleavelandita e micas claras de granulação fina, são pouco volumosas, ainda que noutros sejam maiores e mais conspícuas. Nestes casos, já se pode ter como acessórios dos corpos de substituição turmalinas coradas, cassiterita e columbo-tantalitas com teores em $\mathrm{Ta}_{2} \mathrm{O}_{5}$ mais altos que nas das unidades de cristalização primária.

\section{GEOQUIMICA DE BERILOS, FELDSPATOS E MICAS} DA PROVÍNCIA ORIENTAL Considerando a granula. ção pegmatítica, é muito difícil amostrar estas rochas para estudos geoquímicos. Por isso, no pressuposto de que os minerais representam as condições de cristalização em ter. mos de composição $(X)$, pressão $(P)$ e temperatura $(T)$, usam-se estes muitas vezes para definir as características geoquímicas da evolução pegmatítica.

Para efeitos comparativos, deve ter-se em conta que o material pegmatítico, uma vez posicionado no nível crustal de cristalização, sofre evolução interna que permite o aparecimento de gerações distintas de um mesmo mineral. Ao fazer comparações das características geoquímicas dos minerais, esta realidade é muitas vezes esquecida. Daqui decorre que só tem sentido fazer comparações utilizando minerais que tenham cristalizado em condições semelhantes. Isto implica que a coleta de material tem de levar em conta as características estruturais dos corpos pegmatíticos e tam. bém as de seu enquadramento geológico. Se isto se fizesse sistematicamente, os estudos mineralógicos e geoquímicos ganhariam sua verdadeira dimensão petrológica e passariam a ser realmente complementares dos dados obtidos por outras disciplinas.

\section{Geoquímica de berilos e seu significado petrológico e me-} talogenético $O$ teor em álcalis nos berilos reflete não sర์ as características geoquímicas do material pegmatítico parente (Cerný 1975, Correia Neves et al. 1984) mas também a ampla variação composicional dos berilos dentro do mesmo corpo pegmatítico e até mesmo cristal (Hurlbut Jr. \& Wenden 1951, Cerný \& Simpson 1977, Correia Neves et al. 1984). Por isso, na figura 3 , as amostras 115-A, 115.B, 279-A e 279-B ocupam pontos diferentes. Assim, a amostra 
279-B (Lavra Faria a oeste de Governador Valadares) corresponde a um berilo levemente róseo associado a corpos de substituição, enquanto que a 279-A corresponde a berilo azulado prismático da cristalização inicial. Os berilos da Província Oriental estudados até o presente (Sampaio Filho, et al. 1973, Correia Neves et al. 1984, Marciano 1985), nas sistemáticas de Beus (1960) e Cĕrný (1975), situam-se no grupo IV, com exceção dos berilos (115-A, 115-B, 391-C e Maxixe) que caem no grupo V. Este últimos foram coletados em pegmatitos muito diferenciados e ricos em minerais de lítio em césio (Sá 1977, Sá \& Ellert 1981).

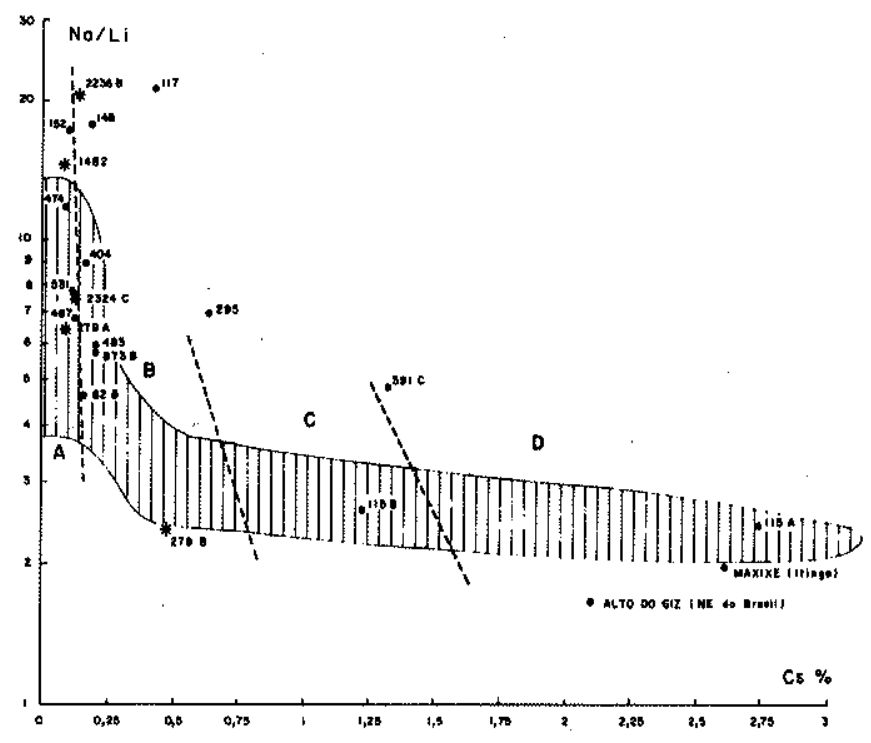

Figura 3 - Representação no diagrama de Trueman \& Cerný (1982) de berilos brasileiros (berilos estudados: Correia Neves et al. 1984; 'Marciano 1985). Pegmatitos (A, estéreis, portadores de $\mathrm{Be}, \mathrm{Nb}$ e $\mathrm{Ta}$ e pobres em álcalis raros; $B$, com Be e ricos em álcalis raros; $C$, com espodumênio; $e D$, mineralizados em $L i, R b, C s, B e$ e $T a$ )

Nos berilos, à medida que o teor em $\mathrm{Li}$ aumenta, a razão $\mathrm{Na} / \mathrm{Li}$ cai drasticamente (Cërný 1975, Trueman \& Cerný 1982). A maior parte dos berilos estudados com elevados valores da razão $\mathrm{Na} / \mathrm{Li}$, projeta-se na fronteira entre os campos A e B (fig. 3) do diagrama. Estes correspondem a pegmatitos pouco diferenciados, estéreis e portadores de $\mathrm{Be}, \mathrm{Nb}$ e $\mathrm{Ta}$, mas relativamente pobres em álcalis raros. Os resultados obtidos mostram que dos pegmatitos estudados, só os de Itinga apresentam berilos cujo teor em álcalis é compativel com concentrações razoáveis em $\mathrm{Li}$ e $\mathrm{Cs}$ nos corpos pegmatíticos correspondentes, como a mineralogia dos corpos alíás revelou (Sá 1977, Sá \& Ellert 1981).

Os berilos do distrito pegmatítico de Itambé estudados por Sampaio Filho et al. (1973) têm valores para a relação $\mathrm{Na} / \mathrm{Li}$ quase todos maiores que 3,43 . Estes autores não apresentam determinaçōes quantitativas para o $\mathrm{Cs}$, mas admitem que os berilos estudados têm teores em Cs inferiores a $500 \mathrm{ppm}$. Isso permite colocar também os pegmatitos portadores destes berilos nos grupos A e B de Trueman \& Černý (1982), antes dos do grupo $\mathbf{C}$ dos pegmatitos portadores de espodumênio (Fig. 3). Assim, a região é potencialmente pouco interessante para minérios de $\mathrm{Li}$ e Cs. Esta conclusão parece ser corroborada pelo relatório técnico sobre os pegmatitos de Itambé (Andrade et al. 1977).
Geoquímica de feldspatos pertiticos e seu significado petrologico e metalogenético Os teores em $\mathrm{Rb}$ e $\mathrm{Ba}$ nos feldspatos pertíticos, bem como as relações $K / \mathrm{Rb}$ e $\mathbf{R b} / \mathbf{B a}$, desde há muito são utilizados não só para interpretar a evolução interna dos corpos pegmatíticos (Correia Neves 1964, Correia Neves et al. 1980a) mas também, quando considerados regionalmente, para evidenciar as características metalogenéticas e a especialização dos pegmatitos em elementos-raros, tais como $\mathrm{Li}, \mathrm{Cs}, \mathrm{Ta}, \mathrm{Hf}, \mathrm{Sb}, \mathrm{Bi}, \mathrm{Sn}$ e $\mathrm{Rb}$ (Correia Neves et al. 1972, Lopes Nunes 1973, Shmakin 1979).

Para fundamentar as presentes interpretações relativas à Província Oriental, foram usados dados de Sá(1977), Correia Neves (1980), Correia Neves et al. (1980a), Wegner (1983), Pedrosa Soares (1984) e Marciano (1985). Esses dados mostram uma clara distinção entre as geraçð̃es dos feldspatos no interior do mesmo corpo. As amostras coletadas nas unidades estruturais mais exteriores estão normalmente enriquecidas em Ba e sempre empobrecidas em $\mathrm{Rb}$, quando comparadas com as das unidades mais interiores. Essas relaçōes têm sido interpretadas (Correia Neves 1964, 1980, Correia Neves et al. 1972, 1980a) como significando que, no processo da evolução interna dos pegmatitos, a cristalização fracionada tem muita importância, embora não seja o único mecanismo atuante no decurso dessa evolução (Uebel 1977, Jahns 1982).

$\mathrm{O}$ padrão regional das razões $\mathrm{K} / \mathrm{Rb}$ e $\mathrm{Rb} / \mathrm{Ba}$ é principalmente afetado pelos seguintes fatores: 1) composição do material pegmatítico parente; 2) composição do material granítico parente do qual o pegmatito se diferenciou; 3 ) distância do corpo pegmatítico relativamente ao granito parente (os pegmatitos afastados do granito parente são geralmente intrusivos nas rochas metamórficas encaixantes dos granitos); 4) grau de metamorfismo da rocha encaixante dos pegmatitos; 5) tamanho do corpo pegmatítico que favorece a diferenciação interna; 6 ) condições de $P$ e $T$ para os quais o material pegmatítico se separa do granito parente; e 7) natureza do material que, por anatexia direta, origina pegmatitos que ocorrem nos terrenos de alto grau de metamorfismo sem ligação imediata com granitóides intrusivos.

Para facilitar a interpretação, as razões $K / R b$ foram representadas graficamente considerando as seguintes associações: 1) pegmatitos de Coronel Murta encaixados quer em granitóides quer em metamorfitos e pegmatitos de Itinga (Fig. 4); 2) pegmatitos de Marilac (Fig. 5); e 3) pegmatitos de Galiléia-Conselheiro Pena (Fig. 6).

No distrito pegmatítico de Araçuaí nota-se tendência para a razão $\mathrm{K} / \mathrm{Rb}$ diminuir quando se passa dos pegmatitos encaixados em granitos para os intrudidos nos metamorfi. tos, sendo os de Itinga (mais diferenciados) os que apresentam menores valores (Fig. 4).

No campo pegmatítico de Marilac, só as pertitas da Lavra Faria apresentam teores em $\mathrm{Rb}$ que variam de cerca de 800 a 4.500 ppm (Fig. 5). Em sua maior parte estes são, porém, inferiores a $1.800 \mathrm{ppm}$. Isso mostra a pouca evolução sofrida pelo material pegmatítico que, nesta região, se considera de origem anatética. Casos como os da Lavra Faria poderão ser explicados pela influência particular dos fatores 1,5 e 7 já referidos.

No campo pegmatítico de Galiléia-Conselheiro Pena, onde os pegmatitos se consideram relacionados aos granitóides (Barbosa et al. 1966), a faixa de variação do $\mathrm{Rb}$ vai de 270 a 4.400 ppm (Fig. 6). Estes valores a colocam mais 


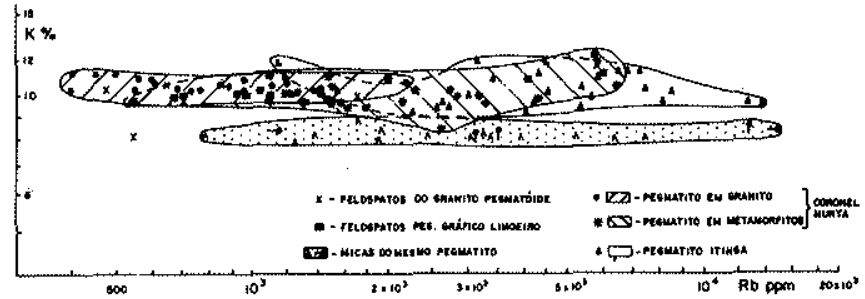

Figura 4 -Distribuição dos $K$ e $\mathrm{Rb}$ em pertitas e micas pegmatiticas de A raçuai

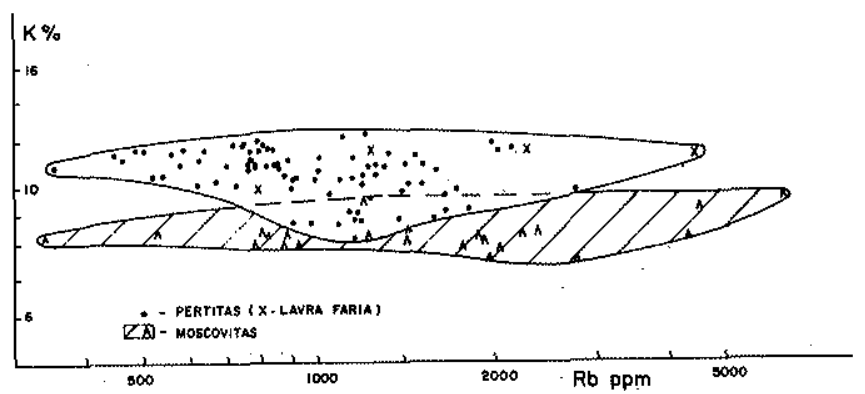

Figura 5 - Distribuição dos $K$ e $R b$ em pertitas e micas pegmatiticas de Marilac

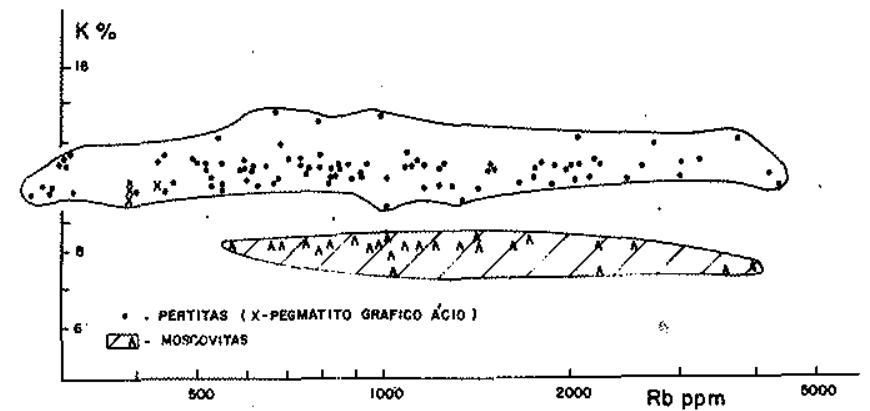

Figura 6 - Distribuição dos $K$ e Rb em pertitas e micas pegmatiticas de Galiléia-Conselheiro Pena

para a esquerda do que a dos pegmatitos de Coronel Murta, encaixados em granitos, o que deve traduzir o fato de que na região de Galiléia afloram rochas tonalíticas não encontradas em Coronel Murta. Em seu limite superior, a faixa não atinge também sequer os limites de variação observados nos pegmatitos de Coronel Murta encaixados em metamorfitos e muito menos os dos pegmatitos de Itinga.

Para interpretar a distribuição do Ba utilizamos os dados analíticos de Correia Neves (1980) e de Wegner (1983).

Como seria de esperar existe uma correlação negativa na distribuição do $\mathrm{Ba}$ em função do Rb (Fig. 7), apesar de se observar uma forte dispersão dos dados. $\mathrm{Da}$ análise desta figura pode-se individualizar os seguintes domínios: 1) um que contém praticamente todos os feldspatos de Marilac e muitos de Galiléia-Conselheiro Pena, caracterizado por teores relativamente baixos em $\mathrm{Ba}$ e em $\mathrm{Rb}(<1.500 \mathrm{ppm}) ; 2)$ outro, o dos feldspatos dos pegmatitos de Coronel Murta encaixados em granitóides parentes, com teores altos em Ba e baixos ( $<1.000 \mathrm{ppm}$ ) em Rb; e 3) ainda outro, em que se destacam os feldspatos dos pegmatitos de Itinga com teores muito altos em $\mathrm{Rb}$ e baixos em $\mathrm{Ba}$.

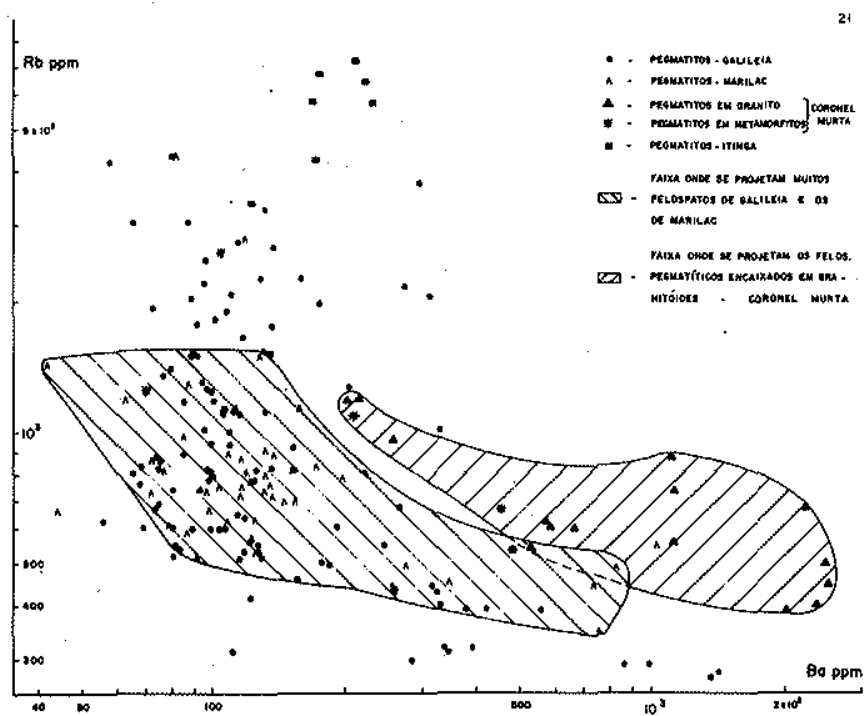

Figura 7 - Distribuição dos $R b$ e Ba em pertitas pegmatiticas de Arafuai, Marilac e Galiléia-Conselheiro Pena

Comparando os padrões de distribuição dos $\mathrm{K} / \mathrm{Rb}$ e $\mathrm{Rb} / \mathrm{Ba}$, nos feldspatos da Província Oriental, com o da va riação de $\mathrm{Na} / \mathrm{Li}-\mathrm{Cs}$ nos berilos, novamente aparece destacado o campo pegmatítico de Itinga notabilizado por sua produção em minérios de $\mathrm{Li}, \mathrm{Sn}, \mathrm{Cs}$ e Ta.

Os pegmatitos da Província Oriental, cujos feldspatos, em termos de teores em $\mathrm{Rb}$ e $\mathrm{Ba}$, mais se aproximarem dos de Itinga, serão os potencialmente mais ricos para os miné. rios atrás referidos.

Geoquímica de micas claras e seu significado petrológico e metalogenético As micas, por sua estrutura cristalina e largo espectro de cristalização, do começo ao fim da evolução dos pegmatitos, são fases minerais adequadas para analisar não só a evolução interna dos corpos mas também seu potencial metalogenético (Lopes Nunes 1973).

Os elementos $\mathrm{Rb}$ e Cs em substituição do $\mathrm{K}$ e o $\mathrm{Li}$ na camada octaédrica das micas são particularmente concentrados na estrutura desses minerais.

Neste trabaiho considera-se apenas as razões $\mathrm{K} / \mathrm{Rb}$ nas micas da Província Oriental (Figs. 4, 5 e 6). A amostragem estudada não é ainda representativa e por isso são feitas as seguintes ressalvas:

- No distrito de Araçuaí não foram estudadas lepidolitas de Itinga.

- Dentro de um mesmo corpo pegmatítico o fracionamen. to em $\mathrm{Rb}$ pode ser muito grande, como acontece na região de Coronel Murta (Fig. 4).

- No distrito de Governador Valadares dominam as mosco. vitas, o que é um sinal de pouco enriquecimento em $\mathrm{Li}$ e $\mathrm{Cs}$ neste distrito. 
RELAÇÕES ENTRE PEGMATITOS E GRANITOS DA PROVÍNCIA ORIENTAL Analisando a informação geológica existente no momento, consegue-se mostrar um estreito relacionamento genético entre granitos e pegmatitos no distrito pegmatítico de Araçuaí e no campo pegmatítico de Galiéia-Conselheiro Pena. Não se pode afirmar o mesmo no caso do campo pegmatítico de Marilac, onde os pegmatitos, encaixados em metamorfitos, encontram-se muito afastados de granitos isotrópicos, dos quais poderiam ser diferenciados tardios.

As relações de parentesco entre granitos e pegmatitos estão bem documentadas quer no distrito pegmatítico de Araçuaí (Sá 1977, Sá \& Ellert 1981, Correia Neves et al. 1982a, 1982b, Pedrosa Soares 1984, Costa et al. 1984), quer no campo pegmatítico de Galiléia-Conselheiro Pena (Barbosa et al. 1964, 1966, Moura et al. 1978a, 1978b, Fanton et al. 1978, Correia Neves et al. 1980 b).

Em ambas as áreas encontram-se pegmatitos posicionados quer nos granitóides, onde formam bolsões ou preenchem fraturas, quer nos metamorfitos encaixantes, onde formam corpos tabulares ou lenticulares.

Distrito de Araçuaí Nesta região afloram biotita-moscovita granitos $\left(\gamma_{\mathrm{B}}\right)$, moscovita-biotita granitos $\left(\gamma_{\mathrm{M}}\right)$ e granitos pegmatóides. Como já vimos, esses granitóides são predominantemente granitos e ocorrem também granodioritos.

No contato com os metamorfitos encaixantes encontram-se granitos pegmatóides, granitóides turmalínicos e granitóides muito ricos em moscovita e sem biotita (Sá 1977, Sá \& Ellert 1981, Pedrosa Soares 1984).

Na região de Coronel Murta, os granitóides, meta- $\left(\gamma_{\mathrm{B}}\right)$ a peraluminosos, são alcalinos e normalmente mais ricos em $\mathrm{K}$ que em Na, e os granitos moscovíticos têm teores mais elevados em $\mathrm{SiO}_{2}$ que os biotíticos. Em termos de minerais normativos, os granitos $\left(\gamma_{\mathrm{B}}\right)$ não apresentam coríndon, contêm diopsídio e altas porcentagens de hematita e ilmenita. Os granitóides $\left(\gamma_{\mathrm{M}}\right)$ contêm coríndon, raramente diopsídio e baixas porcentagens de hematita e ilmenita. Os granitóides dos contatos sempre apresentam coríndon normativo. Os biotitas granitóides são, do ponto de vista petroquímico, muito mais homogêneos que os moscovita granitóides, que mostram claros sinais de metassomatismo potássico (Pedrosa Soares 1984), deutérico ou não. Essses processos metassomáticos-magmáticos são também evidenciados pela acentuada diminuição dos conteúdos globais dos elementos de terras-raras, segundo a sequeência biotita granito $\rightarrow$ moscovita granito $\rightarrow$ albita-turmalina granito $\rightarrow$ granito pegmatóide (Dutra et al. 1985).

Os granitos de Itinga são também biotíticos e tornam-se mais moscovíticos na proximidade do contato com os metamorfitos encaixantes (Sá 1977, Sá \& Ellert 1981). Esta, aliás, parece ser uma feição regional.

$\mathrm{O}$ diagrama da figura $8 \mathrm{~A}$ mostra que os biotitas granitos de Itinga têm teores em $\mathrm{Mg}$ entre os dos granitos $\left(\gamma_{\mathrm{B}}\right)$ e $\left(\gamma_{\mathrm{M}}\right)$ de Coronel Murta. Os teores em Li caem na mesma faixa para os três granitos.

O diagrama da figura 8B mostra que os biotita granitos de Itinga apresentam razões $\mathrm{K} / \mathrm{Rb}$ que evidenciam uma maior diferenciação quando comparados com os biotita-moscovita granitos $\left(\gamma_{\mathrm{B}}\right)$ de Coronel Murta.

Os granitos de Itinga apresentam idades $\mathrm{Rb}$-Sr de 538 Ma e os pegmatitos litiníferos da mesma área têm moscovi-

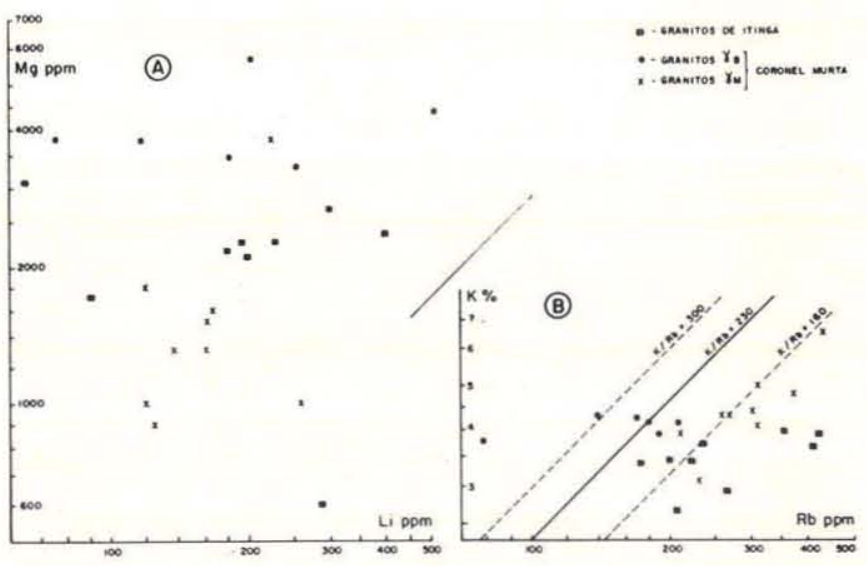

Figura 8 - Distribuição (A dos $\mathrm{Mg}$ e $\mathrm{Li} ; \mathrm{B} \operatorname{dos} \mathrm{K}$ e Rb) em granitos de Araçuai

tas cuja idade K-Ar é de cerca de 480 Ma (Sá 1977, Sá \& Ellert 1981).

A existência de 1) deformação estrutural caracterizada pelo aparecimento de anti- e sinformes abertos sobrepondo-se ao dobramento isoclinal desenvolvido durante o metamorfismo regional; 2) freqüente verticalização da xistosidade nas vizinhanças de muitos corpos granitóides; 3 ) faixas de migmatitos de injeção; 4) corpos graníticos com margem de esfriamento rápido de fina granulação; 5) xenólitos e roof-pendants de micaxistos, comuns no interior dos granitóides; 6) características de metamorfismo de contato, que originou diversos tipos de "hornfelsitos"; e 7) uma seqüência de idades $\mathrm{Rb}$-Sr desde a do metamorfismo regional (673 $\mathrm{Ma}$.), passando pela dos granitos ( $538 \mathrm{Ma}$ ), até a do material pegmatítico (480 Ma , K-Ar) evidenciam que os granitóides de Araçuí são intrusivos, tardi- a pós-tectônicos, nos metamorfitos encaixantes (Sá 1977, Sá \& Ellert 1981, Correia Neves et al. 1982a, 1982b, Pedrosa Soares et al. 1984).

Campo Pegmatítico de Galiléia-Conselheiro Pena $\mathrm{O}$ conhecimento petrográfico e geoquímico dos granitóides e pegmatitos é menos detalhado que o do distrito pegmatítico de Araçuaí, excetuando os estudos de minerais raros, alguns novos para a ciência (Pough 1945, Lindberg 1949, Pécora \& Fahey 1949, Lindberg \& Murata 1953, Lindberg et al, 1953, Lindberg \& Pécora 1955).

Entre os granitóides desta região foram descritos tonalitos, granodioritos e granitos (Barbosa et al. 1964). Destes, os tonalitos e os granodioritos foram considerados como fácies diferentes dentro do mesmo material granítico (Moura et al. 1978a). Utilizando composições modais de Barbosa et al. (1964), construiu-se o diagrama Q-A-P da figura 9 , em que se nota distribuição dessas rochas pelos campos tonalito, granodiorito e, com predomínio, granito. Os tonalitos são praticamente desprovidos de moscovita e muito ricos em biotita com teores entre $13 \%$ e $20 \%$. Mesmo no granito Urucum, comumente, a biotita domina sobre a moscovita. São referidos, ainda que mais raramente, granitos em que a moscovita domina relativamente à biotita (Barbosa $e t$ al. 1964).

A idade da gênese dos granitos da região pode perceber-se dos estudos de Gerken Sobrinho \& Cordani (1964) sobre datações K-Ar em biotitas de quatro tonalitos e dois granodioritos. $\mathrm{O}$ valor médio da idade é nos tonalitos de 


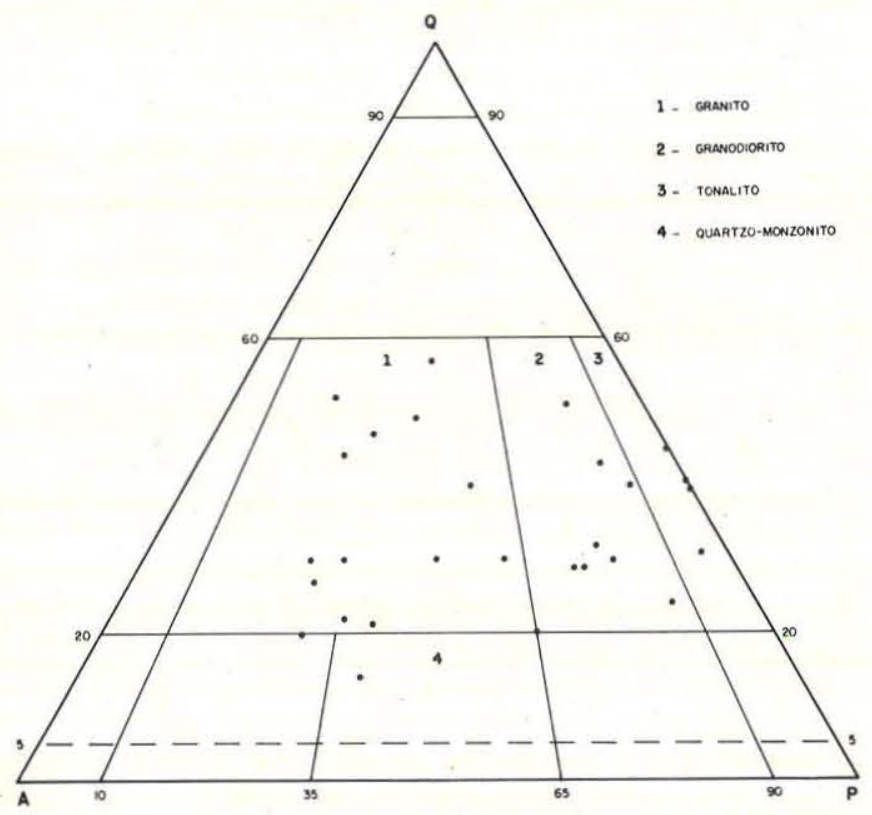

Figura 9 - Representação Q-A-P de granitóides de Galiléia

$450 \pm 13,5$ Ma e nos granodioritos, de $512 \pm 15,3 \mathrm{Ma}$. Estes valores, que significam o esfriamento, são inferiores à idade da cristalização das rochas. Em zirconitas do tonalito Galiléia foi determinada uma idade $\alpha-\mathrm{Pb}$ de 550 a $600 \mathrm{Ma}$ (Barbosa et al. 1966).

Pela existência de 1) numerosas inclusões máficas, particularmente nos tonalitos, consideradas como autólitos (Barbosa et al. 1964) e descritas como tendo a mesma mineralogia dos xistos São Tomé (Moura et al. 1978a); 2) verdadeiros xenólitos de xisto São Tomé e mesmo de granodiorito dentro do granito Urucum; 3) orientação das lamelas de biotita nos tonalitos e granodioritos; 4) complexas relações de contato entre diversos tipos de granitóides; e 5) determinações de idade em zirconitas e em biotitas dos tonalitos Galiléia e granodiorito Palmital e em moscovita de pegmatito, conclui-se que na região afloram granitos sincinemáticos e tarditectônicos (granito Urucum) de idade brasiliana, intrusivos nos xistos São Tomé.

Os pegmatitos importantes da área de Galiléia relacionam-se com os granito Urucum e granodiorito Palmital (Barbosa et al. 1966).

Ao mesmo ciclo granitogênico, caracterizado em Araçuaí e Galiléia, pertencem os granitos tarditectônicos intrusivos do Morro Ibituruna (Governador Valadares), de Ecoporanga e de Umburatiba, estes últimos situados a NE e SW de Teófilo Otôni, respectivamente. Os do Ibituruna deram uma isócrona Rb-Sr de $560 \mathrm{Ma}$ com (RI de 0,7108) e os dois últimos definem outra de $460 \mathrm{Ma}$ (RI de 0,718) (Besang et al. 1977), típica de material crustal remobilizado.

PEGMATITOS DA PROVIŃNCIA ORIENTAL E METAMORFISMO DE SUAS ENCAIXANTES Fundamentados na análise dos terrenos metamórficos encaixantes de diversos tipos de campos pegmatíticos, os geólogos soviéticos (Ginsburg et al. 1979) reconheceram que a gênese dos pegmatitos ricos em mica se restringia aos ambientes barrowianos de moderados valores de $P$ e gradiente térmico e que a formação dos pegmatitos ricos em elementos raros se daria em ambientes tipo Abukuma de forte gradiente térmi- co e de baixa pressão. Os primeiros estão confinados em micaxistos com cianita e almandina, fora do campo de estabilidade da estaurolita e abaixo das isógradas da silimanita. Os pegmatitos mais fracionados, com berilo, situam-se em regra nas rochas com estaurolita enquanto os tipos cerâmicos estéreis tendem a se localizar no campo da silimanita (A e C, Fig. 10). Os segundos, com elementos raros, restringem-se às rochas contendo andaluzita + cordierita + moscovita e só os membros estéreis se encontram já no campo de estabilidade da silimanita (1 a 4, Fig. 10). Algumas dessas áreas pegmatíticas localizam-se em terrenos de pressões mais altas marcadas pela presença de estaurolita e espodumêmio (I e III, Fig. 10).

Os pegmatitos de Coronel Murta e Itinga posicionaram-se a profundidades correspondentes às do metamorfismo térmico causado pelos granitos em ambas as áreas. $\mathrm{Na}$ região de Itinga é possível pensar-se, de acordo com os dados geocronológicos existentes, que o metamorfismo térmico ocorreu cerca de $100 \mathrm{Ma}$, após o clímax do metamorfismo regional que atingiu a fácies anfibolito. Isto implica que, quando os metamorfitos sofreram a ação térmica dos granitos intrusivos, não se puderam desenvolver as típicas auréolas de contato descritas na literatura (Winkler 1979, Turner 1981). Tal situação é particularmente evidenciada pela preservação de estruturas originadas durante o metamorfismo regional mesmo quando, como se observa em Itinga, os metapelitos ficam repletos de porfiroblastos de andaluzita e/ou cordierita (Costa et al. 1984, Pedrosa Soares 1984).

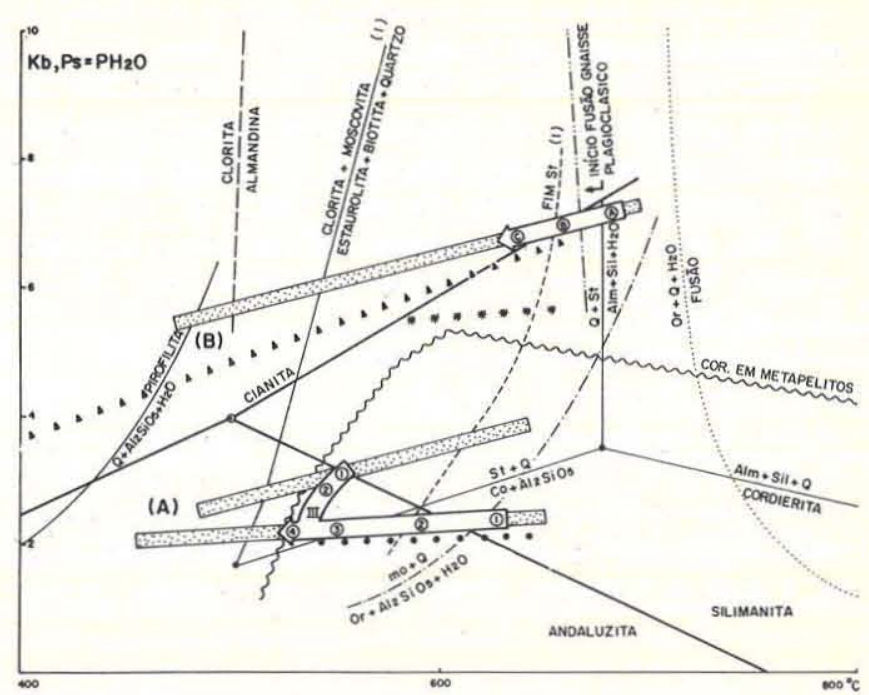

Figura 10 - Localização do metamorfismo regional dos grupos Macaúbaș e Salinas ( $\Delta \Delta \Delta \Delta \Delta \Delta \Delta \Delta \Delta)$ e térmico das áreas de Coronel Murta (**** ) e Itinga (•....), e dos pegmatitos (setas) em faixas de evolução metamórfica (pontilhado), num diagrama $\mathrm{P}, \mathrm{T}$, modificado de Winkler (1979), Turner (1981) e Cerny (1982b). (A) Abukuma; (B) Barrowiano; polimorfos $\mathrm{Al}_{2} \mathrm{SiO}_{5}$ (Holdaway 1971); (1) Hoschek (1969). Pegmatitos de nivel intermediário (1, estéril; 2, com berilo; III e 3, com espodumênio; 4, com petalita, Ta e Cs). Pegmatitos de nivel profundo ( $A$, cerâmico; $B$, com moscovita; $C$, com berilo). As faixas pontilhadas de Ginsburg et al. (1979) foram deslocadas para as adequar à petrologia experimental $e$ aos valores de pressão usados na delimitação das classes pegmatiticas 
As paragêneses observadas em metapelitos de Itinga (Costa et al. 1984), em contato com os granitos, permitiram individualizar três áreas caracterizadas pelos seguintes minerais: 1) andaluzita-estaurolita, 2) andaluzita-cordierita e 3) silimanita-cordierita, a partir dos quais se localizou, na figura 10 , a evolução do metamorfismo térmico. Os valores de $P$ e $T$ correspondentes são inferiores aos admitidos por Miyashiro (1973) para os campos de estabilidade dos minerais referidos. No campo proposto considerou-se a instabilidade da estaurolita face a andaluzita (Hoschek 1969) e atendeu-se que a presença desta implica valores de $P$ inferiores a $3,5 \mathrm{~kb}$ (Turner 1981).

Nas paragêneses observadas nas faixas de metamorfismo térmico de Coronel Murta, não se caracterizaram andaluzita e cordierita e, portanto, lá os granitos se posicionaram a maior profundidade que os de Itinga, como mostra a figura 10. De acordo com alguns autores (Holdaway 1971, Richardson 1968, Turner 1981), pode-se ainda pensar que os metamorfitos de Coronel Murta estavam sujeitos a pressões superiores a $3,5 \mathrm{~kb}$ quando foram intrudidos pelos granitos e, como não se caracterizou o aparecimento de silimanita resultante da reação entre moscovita e quartzo, que as temperaturas máximas durante 0 posicionamento não devem ter ultrapassado os $650^{\circ} \mathrm{C}-700^{\circ} \mathrm{C}$, consideradas pressões de 3,5 a $6 \mathrm{~kb}$ (Pedrosa Soares et al. 1984).

As evidências atualmente disponíveis não permitem caracterizar fenômenos de anatexia em Coronel Murta ou Itinga (Pedrosa Soares et al. 1984, Costa et al. 1984).

A localização, na figura 10 , das condições de metamorfismo regional dos grupos Macaúbas e Salinas foi discutida por Pedrosa Soares et al. (1984).

Considerando o que foi referido acima, os granitos dos campos pegmatíticos de Araçuaí devem ter-se posicionado entre 13 e $20 \mathrm{~km}$ (Coronel Murta) e 7 e $10 \mathrm{~km}$ (Itinga), o que implica a existência de uma falha de orientação SW-NE, de acordo com o padrão regional, que permitiu as relações topográficas atualmente existentes entre os dois tipos de granito.

Um outro argumento favorável ao posicionamento em nível crustal mais alto dos, ao menos em parte, corpos graníticos de Itinga relativamente aos de Coronel Murta reside no fato de que em Itinga, num grande número de pegmatitos, ocorre petalita, o que não acontece em Coronel Murta, onde os pegmatitos apresentam espodumênio. Como se sabe, a petalita é mineral estável a menores pressões em rela ção ao espodumênio (London \& Burt 1982, Skvortsov et al. 1984). As características geoquímicas dos granitos de Coronel Murta e Itinga (Figs. 8A e 8B) parecem também estar de acordo com esta conclusão.

No campo pegmatítico de Marilac não se dispõem de estudos detalhados sobre o metamorfismo, porém as rochas aflorantes são predominantemente gnaisses, anfibolitos, migmatitos e mesmo charnoquitos (Schobbenhaus et al. 1978a), o que permite, pelo menos tentativamente, colo. car seus pegmatitos entre os de anatexia direta portadores de moscovita.

$\mathrm{Na}$ região de Galiléia.Conselheiro Pena, os pegmatitos encaixam em granitóides e, sobretudo, em biotita xistos granatíferos, localmente enriquecidos em estaurolita e/ou silimanita, pertencentes ao Grupo Rio Doce. Os tipos mais feldspáticos dos micaxistos São Tomé, passando a gnaisses, contêm silimanita (Barbosa et al. 1966, Moura et al 1978a).

Considerando as relações entre granitóides e metamorfitos já analisadas anteriormente e as paragêneses acabadas de refletir, o metamorfismo regional que afetou os xistos São Tomé deve ser Barrowiano do tipo do de Coronel Murta.

$O$ afloramento em Galiléia de grandes extensões de tonalitos sintectônicos, não caracterizados em Coronel Murta, e o predomínio da silimanita no termo gnáissico do Grupo Rio Doce levam-nos a pensar que nesta região se tenham atingido níveis de anatexia. Isso faria com que, nela, os pegmatitos se tivessem gerado a maiores profundidades que os de Coronel Murta.

Finalmente, as relações entre granitóides e micaxistos observadas na área de Galiléia-Conselheiro Pena, o tipo de metamorfitos, as determinações de idade já existentes, ainda que escassas, e o carácter sintectônico dos tonalitos e granidioritos permitem pensar que existe um paralelismo estratigráfico entre os grupos Salinas e Rio Doce, o que aliás é já admitido por Schobbenhaus et al. 1978a.

Agradecimentos A realização do presente trabalho foi possível graças a vários auxílios de pesquisa e bolsas concedidas pelo Conselho Nacional de Desenvolvimento Científico e Tecnológico (CNPq) e ainda a auxílios da Coordenação de Pesquisa da Universidade Federal de Minas Gerais (CPq-UFMG), aos quais se agradecem. A datilografia é de Katia Maria Moura Michue Bendezú e os desenhos são de Frederico Rosa e Silva. Aos dois, os nossos agradecimentos.

\section{REFERENCIAS BIBLIOGRAFICAS}

ANDRADE, A.P.; COSTA, A.L.L.; SILVA, E.F.A.; CUNHA, J.C.; MARINHO, M.M. - 1977 - Projeto Itambé-Geologia, Texto 1, Salvador (CBPM), v. 1, 240 p.

BARBOSA, A.L.M. \& GROSSI SAD, J.H. - 1983 - Reinterpretação das "séries" Juiz de Fora e Pararba, em Minas Gerais e Rio de Janeiro. In: SIMP. GEOL. MINAS GERAIS, 2, Belo Horizonte, 1983. Atas... Belo Horizonte, SBG-Núcleo MG. v. 3, p. 1-15.

BARBOSA, A.L.M.; GROSSI SAD, J.H.; MELLO, M.T.V.; TORRES, N. - 1964 - Geologia das Quadriculas de Cuité e Conselheiro Pena, Minas Gerais, Brasil. Relatório de Geosol para o DNPM, RJ, 285 p. (inédito).

BARBOSA, A.L.M.; GROSSI SAD, J.H.; TORRES, N.; MELLO, M.T.V. $-1966 \sim$ Description of the Preliminary Geologic Map of the Middle Rio Doce. In: GUIDEBOOK, Washington, Am. geol. Inst., 1966? (manual preparado para uso dos participan- tes do International Field Institute, Brazil, 1966, pag. irreg.). BESANG, C.; EBERLE, W.G.; LAHNER, L.; LENZ, H.; MUELLER, P.; PAULSEN, S. - 1977 - Radiometrische Altersbestimmungem an Gesteinen aus Minas Gerais und Espírito Santo, Brasilien. Geol. Jahrb., 24:149-179.

BEUS, A.A. - 1960 - Geochemistry of beryllium and genetic types of beryllium deposits. Publ. House Acad. Science, Moscou (em russo).

BRITO NEVES, B.B.; CORDANI, U.G.; TORQUATO, J.R.F. 1980 - Evolução geocronológica do Pré-Cambriano do Estado da Bahia. In: Geologia e Recursos Minerais do Estado da Bahia, Textos Básicos, 3:1-101, Salvador.

CAMERON, E.N.; JAHNS, R.H.; McNAIR, A.; PAGE, L.K. - 1949 - Internal structure of granitic pegmatites. Econ. Geol. Monogr., 2, 115p.

CERNY, P. - 1975 - Alkali variations in pegmatitic beryls and 
their petrogenetic implications. Neus Jahrb. Mineral. Abh., 123:198-212.

CERNY, P. - 1982a - Anatomy and classification of granitic pegmatites. Min. Assoc. Canada Short Course Handbook, 8:1-39.

CERNY, P. - 1982b - Petrogenesis of granitic pegmatites. Min. Assoc. Canada Short Course Handbook, 8:405-461.

CERNY, P., ed. - 1982 - Granitic Pegmatites in Science and Industry. Min. Assoc. Canada Short Course Handbook, 8:1-555.

CERNY, P. - 1984 - Granitic pegmatites. Monograph Series on Geology of Ore Deposits. In: BROWN, A.C., ed. (in press).

CERNY, P. \& SIMPSON, F.M. - 1977 - The Tanco pegmatite at Bernic Lake, Manitoba. IX. Beryl. Can. Mineral, 15:489-499.

CERNY, P. \& BURT, D.M. - 1984 - Paragenesis, crystallochemical characteristics, and geochemical evolution of micas in granite pegmatites. Mineral Soc. America, Reviews in Mineralogy, 13:257-297.

CORDANI, U.G. - 1973 - Evolução Geologica Pré-Cambriana da Faixa Costeira do Brasil, entre Salvador e Vitória. São Paulo, (Tese de Livre-Docência IG-USP). 98p. (inédita).

CORDANI, U.G. \& TEIXEIRA, W. - 1979 - Comentários sobre as determinações geocronológicas existentes para as regiōes das folhas Rio de Janeiro, Vitória e Iguape. In:DNPM-DGM, Carta geológica do Brasil ao milionésimo. Folha RJ (SF. 23), VIT (SF. 24) e IGU (SG.23):175-207.

CORDANI, U.G.; DELHAL, J.; LEDENT, D. - 1973 - Orogenèses superpossées dans le Précambrien du Brésil Sud-Oriental (États de Rio de Janeiro et de Minas Gerais). Rev. Bras. Geoc., 3(1):1-22.

CORREIA NEVES, J.M. - 1964 - Genese des zonar gebauten Beryllpegmatits von Venturinha (Viseu, Portugal) in geochemischer Sicht. Heid. Beitraege Min. Petro., 10 (Correns v.): 357-373.

CORREIA NEVES, J.M. - 1980 - Compostion and estructural state of feldspars from the eastern pegmatite province of Minas Gerais, Brasil. In: INT. GEOL. CONGR., 26, Paris (inédito).

CORREIA NEVES, J.M. - 1981 - Pegmatitos graniticos; morfologia, mineralogia, geoquímica, gênese e metalogênese. Belo Horin zonte, (Tese apresentada no concurso para professor titular da UFMG), $262 \mathrm{p}$. (inédito).

CORREIA NEVES, J.M. - 1984 - Significado petrológico das gemas de origem pegmatítica. In: CONG. BRAS. GEOL., 33, Rio de Janeiro. SBG, (inédito).

CORREIA NEVES, J.M.; LOPES NUNES, J.E.; LUCAS, D.B. 1972 - Mineralogy and geochemistry of pegmatites from Mozambique (P.E.A.). In: INT. GEOL. CONG., 24. Montreal, 1972. Geochemistry, sect. 10:37-44.

CORREIA NEVES, J.M.; PEDROSA SOARES, A.C.; VALLE, R.R. - 1980a - Geoquímica e gênese do Pegmatito Limoeiro (Virgem da Lapa, MG). In: CONG. BRAS. GEOL., 31, Balneário de Camboriú, 1980. Anais... Balneário de Camboriú, SBG, v. 4 p. 2134-2148.

CORREIA NEVES, J.M.; DUTRA, C.V.; KARFUNKEL, J.; KARFUNKEL, B.; SCHMIDT J.C.; QUEMENEUR, J.J.G.; PEDROSA SOARES, A.C. - 1980b - Mineralogia e geoquímica đo pegmatito Ẽnio (Galiléia, Minas Gerais). An. Acad. Bras. Ci., 52(3):603-616.

CORREIA NEVES, J.M.; QUÉMÉNEUR, J.J.G.; BARAUD, R.; PEDROSA SOARES, A.C.; MONTEIRO, R.L.B.P.; SCLIAR, C. 1982a - Avaliação das provincias pegmatiticas de Minas Gerais; I. Enquadramento geológico. Conv. 227 FINEP/UFMG, Relatório final. 227 p. (inédito).

CORREIA NEVES; J.M.; MONTEIRO, R.L.B.P.; PEDROSA SOARES, A.C. - 1982b - Granitóides da regiảo de Coronel Murta, Minas Gerais, Brasil; I. Petrografia. In: CONG. LATINOAM. GEOL., 5, Buenos Aires, 1982. Actas... Buenos Aires, v.2, p. 133.146.

CORREIA NEVES, J.M.; DUTRA, C.V.; MONTEIRO, R.L.B.P 1984 - Composição química de berilos pegmatíticos do Brasil e seu significado petrológico e metalogenético, Rev. Bras. Geoc., 14(3):137-146.

COSTA, M.T. - 1978 - Mapa Geológico do Estado de Minas Gerais na escala 1:1.000.000 Nota Explicativa Inst. de Geoc. Aplic. (IGA-MG), $32 \mathrm{p}$.

COSTA, A.G.; CORREIA NEVES, J.M.; MUELLER, G. - 1984 Feições polimetamórficas dos metapelitos da região de Itinga,
Minas Gerais. In: CONG. BRAS. GEOL., 33, Rio.de Janeiro, 1984. Anais... SBG, Rio de Janetro, v. 7, 3166-3180 p.

DIRAC, F.M. \& EBERT, H. - 1967 - Isotopic Ages from the Pegmatite Provinces of Eastern Brazil. Nature, 215:948-949.

DUTRA, C.V.; GROSSI SAD, J.H.; PEDROSA SOARES, A.C. 1985 - Terras-Raras em litogeoquímica: I - Esquemas de distribuição de elementos de terras-raras em rochas graníticas do Distrito Pegmatítico Coronel Murta-Virgem da Lapa, Minas Gerais. In: SIMP. BRAS. GEOQ., 3, Ouro Preto, 1985. Bol. Resumos..., Ouro Preto, SBG/CTCGQ, p. 29-31.

FANTON, J.J.; ARIOLI, E.A.; MOURA, OJ.M. - 1978 - Pegmatitos da região da Galiléia-Mendes Pimentel (Minas Gerais). In: CONG. BRAS. GEOL., 30, Recife, 1978. Anais... Recife SBG, v. 4, p. 1770-1781.

GERKEN SOBRINHO, J.K. \& CORDANI, U.G. - 1964 -. Determinaf̧ôes preliminares de idades $K . A r$ em biotitas de rochas grant ticas do Vale do Rio Doce, Minas Gerais. In: BARBOSA et al. 1964,10 p. (inéđito).

GINSBURG, A.I.; TIMOFEYEV, I.N.; L.G. - 1979 - Principles of Geology of the Granitic Pegmatites. Nedra, Moscow, 296 p. (em russo; referido em CERNY \& BURT 1984).

HASUI, I.; CORDANI, U.G.; KAWASHITA, K.; DELHAL, J. 1976 - Geocronologia da regiâo do Médio Rio Doce, MG. In: CONG. BRAS. GEOL., 29, Ouro Preto 1976.Resumos... Ouro Preto, SBG, p. 211-212.

HASUI, Y; SADOWSKI, G.R.; CARNEIRO, C.D.R. - 1978 - A zona marginal do sul do Cráton São Francisco. Publ. Espec. SBG-Núcleo BA, 3:205-224.

HENRICH, E.W. \& BUCHI, S.H. - 1969 - Beryl-chrysoberylsillimanite paragenesis in pegmatites. Indian Mineralogist, 10:1-7.

HOLDAWAY, M.J. - 1971 - Stability of andalusite and the aluminium silicate phase diagram. Amer. J. Sci., 271:97-131.

HOSCHEK, G. - 1969 - The stability of staurolite and chloritoid and their significance in metamorphism of pelitic rocks. Contr. Miner. Petrol., 22:208-232.

HURLBUT, Jr., C.S. \& WENDEN, H.E. - 1951 - Beryl at Mount Mica, Maine. Amer. Mineral, 36: 751-759.

ISSA FILHO, A.; MOURA, O.J.M.; FANTON, J.J, - 1980 - Reconhecimento de pegmatitos da Província Oriental Brasileira, entre Aimorés e Itambacuri, MG. In: CONG. BRAS. GEOL., 31, Balneário đe Camboriú, 1980. Anais..., Balneário đe Camboriú, SBG. . 3, p. 1552-1563.

JAHNS, R.H. - 1982 - Internal evolution of pegmatite bodies. Min. Assoc. Canada Short Course Handbook, 8:293-327.

LINDBERG, M.L. - 1949 - Frondelite and frondelite-rockbridgeite series. Amer. Mineral., 34:541-549.

LINDBERG, M.L. - 1958 - The beryllium content of roscherite from the Sapucaia pegmatite mine, Minas Gerais, Brazil and from other localities. Amer. Mineral., 43:824-838.

LINDBERG, M.L. \& MURATA, K.L. - 1953 - Faheyite, a new phosphate mineral from the Sapucaia pegmatite, Minas Gerais, Brazil. Amer. Mineral, 38: 263-270.

LINDBERG, M.L. \& PECORA, W.T. - 1955 -. Tavorite and Barbosalite, two new phosphate minerals from Minas Gerais, Brazil. Amer. Mineral., 40:492-966.

LINDBERG, M.L.; PECORA, W.T.; BARBOSA, A.L.M. - 1953 Moraesite a new hidrous beryllium phosphate from Minas, Brazil. Amer. Mineral., 38:1126-1133.

LONDON, D. \& BURDT, D.M. - 1982 - Lithium minerals in pegmatites. Min. Assoc. Canada Short Course Handbook, 8:99-133.

LOPES NUNES, J.E. - 1973 - Contribution à l'étude mineralogique et géochimique des pegmatites du Mozambique. Sciences de la Terre, Mém. 26:1-201.

MARCIANO, V.R.P.R.O. - 1985 - Contribuiç̃o ao estudo da mineralogia e geoqu tmica de pegmatitos da regiāo de Governador Valadares, Minas Gerais. São Paulo, (Dissertação de mestrado, IG-USP). 213 p. (inédito).

MISI, A. \& AZEVEDO, H.C.A. - 1971 - A província pegmatítica do extremo-sul da Bahia. In: CONG. BRAS. GEOL., 25, São Paulo, 1971. Resumos das comunicaçóes... São Paulo, SBG, p. 65.

MISI, A. \& AZEVEDO, H.C.A. - 1975 - A província pegmatítica do extremo sul da Bahia. Miner. e Metal., 38 (35a): 6-10.

MIYASHIRO, A. - 1973 - Metamorphism and metamorphic belts. 1. ed., London, George Allen \& Unwin. 492 p. 
MOORE, P.B. \& ITO, J. - 1978 - I. Whiteite, a new species, and a proposed nomenclature for the Jahnsite-Whiteite complex series. II. New data on xanthoxenite. III. Salmonsite discredited. Miner. Magazine, 42(323):309-323.

MOURA, O.J.M.; FANTON, J.J.; ARIOLI, E.A. - 1978a - Geologia da região de Galiléia-Mendes Pimental (Minas Gerais). In: CONG. BRAS. GEOL., 30, Recife, 1978. Anais... Recife, SBG, v.1, p.26-37.

MOURA, O.J.M.; FANTON, J.J.; ARIOLI, E.A. - 1978b - Pesquisa de pegmatitos na Serra do Urucum, Médio Rio Doce, MG. In: CONG. BRAS. GEOL., 30, Recife, 1978. Anais... Recife SBG, v. 4, p. 1836-1850.

ORCIOLI, P.R.A.; GALLEA, C.G.; ESPINDOLA, C.R.; CUNHA, C.H.R. - 1978 - Pegmatitos topázio berilíferos de Mimoso do Sul, ES. In: CONG. BRAS. GEOL., 30, Recife, 1978. Anais... Recife, SBG, v. 4, p. 1553-1567.

PAIVA, G. - 1946 - Províncias pegmatíticas do Brasil. Bol. DNPM-DFPM, 78:13-21.

PÉCORA, W.T. \& FAHEY, J.J. - 1949 - The Córrego Frio pegmatite. Minas Gerais: Scorzalite and Souzalite, two new phosphate minerals. Amer. Mineral., 34:83-93.

PÉCORA, W.T.; KLEPER, H.R.; LARABEE, D.M.; BARBOSA, A.L.M.; FRAYHA, R. - 1950 - Mica deposits in Minas Gerais, Brasil. U.S.Geol. Survey Bull., 964-C:1-305.

PEDREIRA, A.J.; KISHIDA, A.; TORQUATO, J.R.; MASCARENHAS, J.F. - 1978 - Inventário e reavaliação do conhecimento geológico da parte central do Cráton São Francisco, SBG-Núcleo BA. Publ, espec. 3:67-154.

PEDROSA SOARES, A.C. - 1984 - Metamorfismo, granitogênese e mineralizações associadas na região de Coronel Murta, $N E$ de Minas Gerais, Brasil. Salvador, (Dissertação de Mestrado, UnB), $171 \mathrm{p}$. (inédito).

PEDROSA SOARES, A.C.; LEONARDOS, O.H.; CORREIA NEVES, J.M. - 1984 - Aspectos metamórficos de seqüências supracrustais da Faixa Araçuaí em Minas Gerais. In: CONG. BRAS. GEOL., 33, Rio de Janeiro, 1984. Anais... Rio de Janeiro, SBG, v. 7, p. 3056-3068.

PINSON, W.H.; WHITTEMORE, D.O.; FAIRBAIRN, H.W.; HURLEY, P.M. - 1967 - Rb-Sr whole rock ages on rocks near Sete Lagoas, MG, Brazil. Annual Report MIT:37-39.

POUGH, F.H. - 1945 - Brazilianite, a new phosphate mineral. Amer. Mineral. 30:572-582.

PUTZER, H. - 1976 - Metallogenetische Provinzen in Suedamerika. Stuttgart. E. Schweizerbart'sche Verlagsbuchhandlung, $318 \mathrm{p}$.

RICHARDSON, S.W. - 1968 - Staurolite stability in part of the system Fe-Al-Si-O-H. J. Petrol., 9:467-488.

RUDENKO, S.A.; ROMANOV, V.A.; MORAKHOVSKYI, V.N.;

TARASOV, E.B.; GALKIN, G.A.; DOROKHIN, V.K. - 1975 Conditions of formation and controls of distribution of muscovite objects of the North-Baikal muscovite province, and some general problems of pegmatite consolidation. In: SUKOLOV, $\mathrm{YU}$. and some general problems of pegmatite consolidation. In: SUKOLOV, YU. M., ed. Muscovite pegmatites of the U.S.S.R. Nauka, Leningrad. 1984, p. 174-182. (em russo: referido em ČERNÝ \& BURT, 1984).

SÅ, J.H.S. 1977 - Pegmatitos litiniferos da região de Itinga-Araçuai Minas Gerais. São Paulo, (Tese de Doutoramento, IG-USP), 112 p. (inédito).

SÁ, J.H.S. \& ELLERT, R. - 1981 - Pegmatitos do Médio Jequitinhonha, um modelo genético. In: SIMPÓSIO SOBRE O CRÁTON DO SÃO FRANCISCO E SUAS FAIXAS MARGINAIS, Salvador, 1981, Atas..., Salvador, SBG-Núcleo BA, p.199-207.
SAMPAIO FILHO, H.A.; SIGHINOLFI, G.P.; GALLI, E. - $1973-$ Contribution to the crystal chemistry of beryl. Cont. Miner. Petrol., 38:279-290.

SCHOBBENHAUS, C.; SILVA, A.S.; PIMENTEL, E.C.; NEVES, S.B.; COLPAERT, R.; RAMOS O.; DERZE, G.R. - 1978a Carta geológica do Brasil ao milionésimo. Folha SE.24 (Rio Doce). DNPM-DGM.

SCHOBBENHAUS, C.; SILVA, A.S.; MIGNON, R.A.; NEVES, S.B.; LEÃO, E.; PIMENTEL, E.C.; DERZE, G.R. - 1978 - Carto geológica do Brasil ao milionésimo. Folha SE.23 (Belo Horizonte). DNPM-DGM.

SCHOBBENHAUS, C.; CAMPOS, D.A.; DERZE, G.R.; ASMUS, H.E. (coordenadores) - 1981 - Mapa geológico do Brasil e da área oceânica adjacente incluindo depósitos minerais, na escala 1:2.500.000. 4 folhas. DNPM-DGM.

SCHOBBENHAUS, C.; CAMPOS, D.A.; DERZE, C.R.; ASMUS, H.E. (coordenadores) - 1984 - Geologia do Brasil; texto explicativo do Mapa Geológico do Brasil e da área oceânica adjacente incluindo depósitos minerais; escala 1:2.500.000. Brasília, DNPM-DGM, 1984, $501 \mathrm{p}$.

SHMAKIN, B.M. - 1979 - Composition and structural state of $\mathrm{K}$-feldspars from some U.S. pegmatites. Amer. Mineral., 64:49-56.

SIGA Jr., O.; TEIXEIRA, W.; CORDANI, U.G.; KAWASHITA, K.; DELHAL, J. - 1982 - O padrão geológico-geocronológico das rochas de alto grau da parte setentrional da Faixa Ribeira, ao norte do Rio de Janeiro, Brasil. In: CONG. LATINOAMER. GEOL., 5, Buenos Aires, 1982. Actas... v. 1, p. 349-370.

SKVORTSOV, V.A.; KAZ'MIN, L.A.; KARPOV, T.K. - 1984 Mineral equilibria in the system $\mathrm{Li}_{2} \mathrm{O}-\mathrm{Al}_{2} \mathrm{O}_{3} \mathrm{SiO}_{2}-\mathrm{H}_{2} \mathrm{O}$. Intern Geol. Review, 26(5):593-595.

STANTON, R.L. - 1972 - Ore Petrology. New York, McGraw-Hill. $713 \mathrm{p}$.

STRECKEISEN, A.L. - 1973 - Plutonic rocks, classification and nomenclature recommended by IUGS subcomission on the systematics of igneous rocks. Geotimes, 18:(10):26-30.

TEIXEIRA, W. - 1982 - Geochronology of the souhern part of the São Francisco Craton. Rev. Bras. Geoc., 12(1-3): 268-277.

TRUEMAN, D.L. \& CERNY, P. - 1982 - Exploration for rare element granitic pegmatites. Min. Assoc. Canada Short Course Handbook, 8:463-493.

TURNER, F.J. - 1981 - Metamorphic petrology-Mineralogical, field and tectonic aspects. 2.ed., New York, McGraw-Hill Book Co. 254 p.

UEBEL, P.J. - 1977 - Internal structure of pegmatites, its orign and nomenclature. Neues Jahrb. Mineral. Abh., 131:83-113.

WEGNER, R. - 1983 - Spurenelemente in Granitpegmatiten in Bundsstaat Minas Gerais, Brasilien, unter besonderer Beruecksichtigung der Feldspaete. Friburg, (Tese de Doutorado. Univ. Freiburg), 154p. (inédito).

WINKLER, H.G.F. - 1967 - Petrogenesis of metamorphic rocks. 2.ed., New York, Springer-Verlag. 334p.

WINKLER, H.G.F. - 1979 - Petrogenesis of metamorphic rocks, 5.ed. New York, Springer-Verlag. 348p.

MANUSCRITO

Recebido em 17 de fevereiro de 1986 Revisão aceita em 5 de maio de 1986

Nos últimos anos, o grande aumento na geração de informações tornou cada vez mais difícil a aquisição de competência cientifica através da memorização de fatos. Hoje é mais viável aprender os processos que permitem a obtenção de informações...

Vick, T.D., 1978, J. Geol. Educ. 27:15-16. 